\title{
Temporal Patterns of the Two-Dimensional Spatial Trends in Summer Temperature and Monsoon Precipitation of Bangladesh
}

\author{
Avit Kumar Bhowmik \\ Institute for Environmental Sciences, Quantitative Landscape Ecology, University of Koblenz-Landau, Fortstraße 7, \\ 76829 Landau (Pfalz), Germany
}

Correspondence should be addressed to Avit Kumar Bhowmik; bhowmik@uni-landau.de

Received 27 December 2012; Accepted 15 February 2013

Academic Editors: E. Tagaris and F. Yang

Copyright (C) 2013 Avit Kumar Bhowmik. This is an open access article distributed under the Creative Commons Attribution License, which permits unrestricted use, distribution, and reproduction in any medium, provided the original work is properly cited.

\begin{abstract}
Two climate indices, TXx and PRCPTOT, representing the summer maximum temperature and annual total monsoon precipitation, respectively, in Bangladesh were computed. The temperature and precipitation measurements from 34 meteorological stations during the temporal extent of 1948-2007 were applied for indices' computation under thorough quality control. The spatial trends of the indices were analyzed by applying two-dimensional least square approach along latitudes and longitudes of the observation points. The temporal patterns of the spatial trends were identified by temporally interpolating them applying thin plate smoothing spline method. The analyses of TXx identified regional scale spatial trends in the east-west and south-north directions, which were increasing between 1948 and 1980s. After the 1980s the spatial trends started decreasing, and after 2000 the spatial trend along the south-north changed its direction to the north-south and continued until present. The analyses of the PRCPTOT identified spatial trends in the west-east and north-south directions, which were decreasing between 1948 and 1980s and thereafter increasing until present. About half of the spatial trends were significant in F-statistics at or more than $90 \%$ confidence level. Thus, the obtained results indicated a significant climatic shift within the regional scale of the country during the study period.
\end{abstract}

\section{Introduction}

In light of the recent climatic change concern, evidence has been presented that the indices for seasonal temperature and precipitation show augmented responses to the actual mean climatic trend $[1,2]$. The global multidimensional trends of such climate indices have already been analyzed by incorporating several anthropogenic and natural factors, to predict the pattern of climate change [3-5]. As IPCC $[6,7]$ put emphasis on the need for detailed information of regional patterns of climate change, trends in seasonal climatic events and their statistical significance have also been analyzed in different regions of the world, that is, in Nigeria [8], Australia [9], Asia and central Pacific [10], UK [11], and some parts of India [12]. These studies represent that the regional spatiotemporal trends of temperature and precipitation are more complex and significant than the global trends; they are particularly significant for the regions that have already been under climate change stress, such as Bangladesh.
Bangladesh, situated in south-east Asia, is one of the most vulnerable countries of the world regarding the adverse impacts of anthropogenic climate change [13-17]. The total area of the country is 147,570 square kilometer [18], approximately one-fifth of which consists of low-lying coastal zones within one meter of the high water mark [7]. Threats of sea level rise, droughts, floods, and seasonal shifts due to the global warming have been presented in many recent studies on the country [13-17, 19-21]. The mean annual temperature increased during the period of $1895-1980$ by $0.31^{\circ} \mathrm{C}$ [19], and the annual maximum temperature is predicted to be increased by $0.4^{\circ} \mathrm{C}$ and $0.73^{\circ} \mathrm{C}$ by the year of 2050 and 2100 , respectively [20, 21]. Monsoon precipitation is forecasted to be increased, and at the same time winter precipitation is forecasted to be decreased in the coming decades [22, 23].

The temperature and precipitation fields are highly variable in both space and time, and therefore they should include both the two-dimensional space and one-dimensional time into their trend analysis $[24,25]$. To obtain an accurate 
TABLE 1: Name of the meteorological stations in Bangladesh with their longitudes, latitudes, altitudes, and temporal records of TXx and PRCPTOT.

\begin{tabular}{|c|c|c|c|c|c|c|}
\hline NIR & Stations & $\begin{array}{l}\text { Longitude } \\
\text { (dd) }\end{array}$ & $\begin{array}{l}\text { Latitude } \\
\text { (dd) }\end{array}$ & $\begin{array}{l}\text { Altitude } \\
(\mathrm{m})\end{array}$ & TXx record & PRCPTOT record \\
\hline 1 & Barisal & 90.4 & 22.667 & 4 & $\begin{array}{l}\text { 1949-1951, 1953-1954, } \\
1956-1963,1966-2007\end{array}$ & 1949-1951, 1953-1954, 1956-2007 \\
\hline 2 & Bhola & 90.667 & 22.333 & 5 & 1966-1978, 1979-2007 & $1966-2007$ \\
\hline 3 & Bogra & 89.416 & 24.833 & 20 & 1948-1949, 1952, 1954, 1956-2007 & $1948-2007$ \\
\hline 4 & Chandpur & 90.666 & 23.2 & 7 & $\begin{array}{c}\text { 1964, 1966-1971, 1973-1977, } \\
1979,1981-2007\end{array}$ & $\begin{array}{c}1964,1966-1970,1973-1977, \\
1979,1981-2007\end{array}$ \\
\hline 5 & Chittagong & 91.866 & 22.316 & 6 & 1949-2007 & 1949-2007 \\
\hline 6 & Chuadanga & 88.866 & 23.666 & 12 & 1989-2007 & 1989-2007 \\
\hline 7 & Comilla & 91.2 & 23.45 & 10 & 1948-1962, 1964-1966, 1969-2007 & 1948-1962, 1964-1977, 1979-2007 \\
\hline 8 & Cox’s Bazar & 92.033 & 21.417 & 4 & $1948-2007$ & $1948-2007$ \\
\hline 9 & Dhaka & 90.4 & 23.683 & 9 & $1953-1973,1975-2007$ & $1953-1973,1975-2007$ \\
\hline 10 & Dinajpur & 88.616 & 25.583 & 37 & 1948-1972, 1981-2007 & 1948-1972, 1981-2007 \\
\hline 11 & Faridpur & 89.866 & 23.583 & 9 & $1948-2007$ & $1948-2007$ \\
\hline 12 & Feni & 91.4 & 23 & 8 & $1973-2007$ & $1974-2007$ \\
\hline 13 & Hatiya & 91.1 & 22.43 & 4 & $\begin{array}{l}1966-1971,1973-1980 \\
1982-1994,2000-2007\end{array}$ & $\begin{array}{l}1966-1971,1973-1980 \\
1981-1994,1999-2007\end{array}$ \\
\hline 14 & Ishurdi & 89.166 & 24.166 & 14 & 1961-2007 & 1961-1966, 1968-2007 \\
\hline 15 & Jessore & 89.233 & 23.166 & 7 & 1948-1977, 1979-2007 & 1948-1977, 1979-2007 \\
\hline 16 & Khepupara & 90.233 & 21.933 & 9 & 1975-2007 & $1974-2007$ \\
\hline 17 & Khulna & 89.583 & 22.833 & 4 & $\begin{array}{l}1948-1955,1957-1966 \\
1968-1974,1976-2007\end{array}$ & No record \\
\hline 18 & Kutubdia & 91.833 & 21.833 & 7 & 1985-2007 & $1977,1979-1980,1985-2007$ \\
\hline 19 & Madaripur & 90.216 & 23.183 & 13 & $1977-2007$ & $1977-1978,1980-2007$ \\
\hline 20 & Maijdee Court & 91.133 & 22.833 & 6 & $1951-1956,1958-1975,1978-2007$ & $1951-1975,1978-2007$ \\
\hline 21 & Mongla & 89.666 & 22.417 & 2 & $1989-2007$ & 1991-2007 \\
\hline 22 & Mymensingh & 90.416 & 24.766 & 19 & $1948,1950-2007$ & $1948,1951-2007$ \\
\hline 23 & Patuakhali & 90.417 & 22.333 & 3 & 1973, 1975-1979, 1981-2007 & $1973,1975,1977-1979,1981-2007$ \\
\hline 24 & Rajshahi & 88.583 & 24.333 & 20 & 1964-1969, 1971-2007 & $1964-1968,1971-2007$ \\
\hline 25 & Rangamati & 92.216 & 22.583 & 17 & 1957-2007 & 1957-1966, 1969-2007 \\
\hline 26 & Rangpur & 89.3 & 25.7 & 34 & 1957-1967, 1969-1972, 1978-2007 & 1954-1967, 1969-1975, 1976-2007 \\
\hline 27 & Swandip & 91.416 & 22.416 & 6 & 1966-1974, 1976-2002, 2005-2007 & $\begin{array}{l}1966-1974,1976-2002 \\
2004-2007\end{array}$ \\
\hline 28 & Satkhira & 89.166 & 22.683 & 6 & 1948-1954, 1955-1967, 1969-2007 & \\
\hline 29 & Sayedpur & 88.833 & 25.766 & 6 & 1991-2007 & 1991-2007 \\
\hline 30 & Sitakunda & 91.583 & 22.533 & 23 & 1977-2007 & $1977-2007$ \\
\hline 31 & Srimongol & 91.666 & 24.3 & 44 & 1948-1979, 1982-2007 & 1948-1980, 1982-2007 \\
\hline 32 & Sylhet & 91.833 & 24.9 & 10 & $1956-1972,1974-2007$ & $1956-1972,1974-2007$ \\
\hline 33 & Tangail & 89.833 & 24.166 & 20 & 1987-2007 & $1987-2007$ \\
\hline 34 & Teknaf & 92.333 & 20.833 & 6 & 1977-2007 & $1977-2007$ \\
\hline
\end{tabular}

prediction of the trends in climate phenomena conformant to the real earth scenario, a three-dimensional spatiotemporal trend analysis is very important [26, 27]. All the previous studies on Bangladesh climate basically dealt with the onedimensional temporal trend of the climate phenomena and spatial distribution of these temporal trends. No study has so far dealt with the two-dimensional spatial trends and the temporal distribution of the spatial trends of climate.
In addition, Shahid [23] analyzed the one-dimensional temporal trends and their spatial distribution for 15 different precipitation indices, but so far no study has been carried out to analyze the trends of temperature indices. On one hand, the annual mean rainfall varies from $1400 \mathrm{~mm}$ in the west to more than $4300 \mathrm{~mm}$ in the east of the country [22, 23]. On the other hand, the north-west division of Bangladesh-Rajshahi experiences the highest temperature in summer which causes 

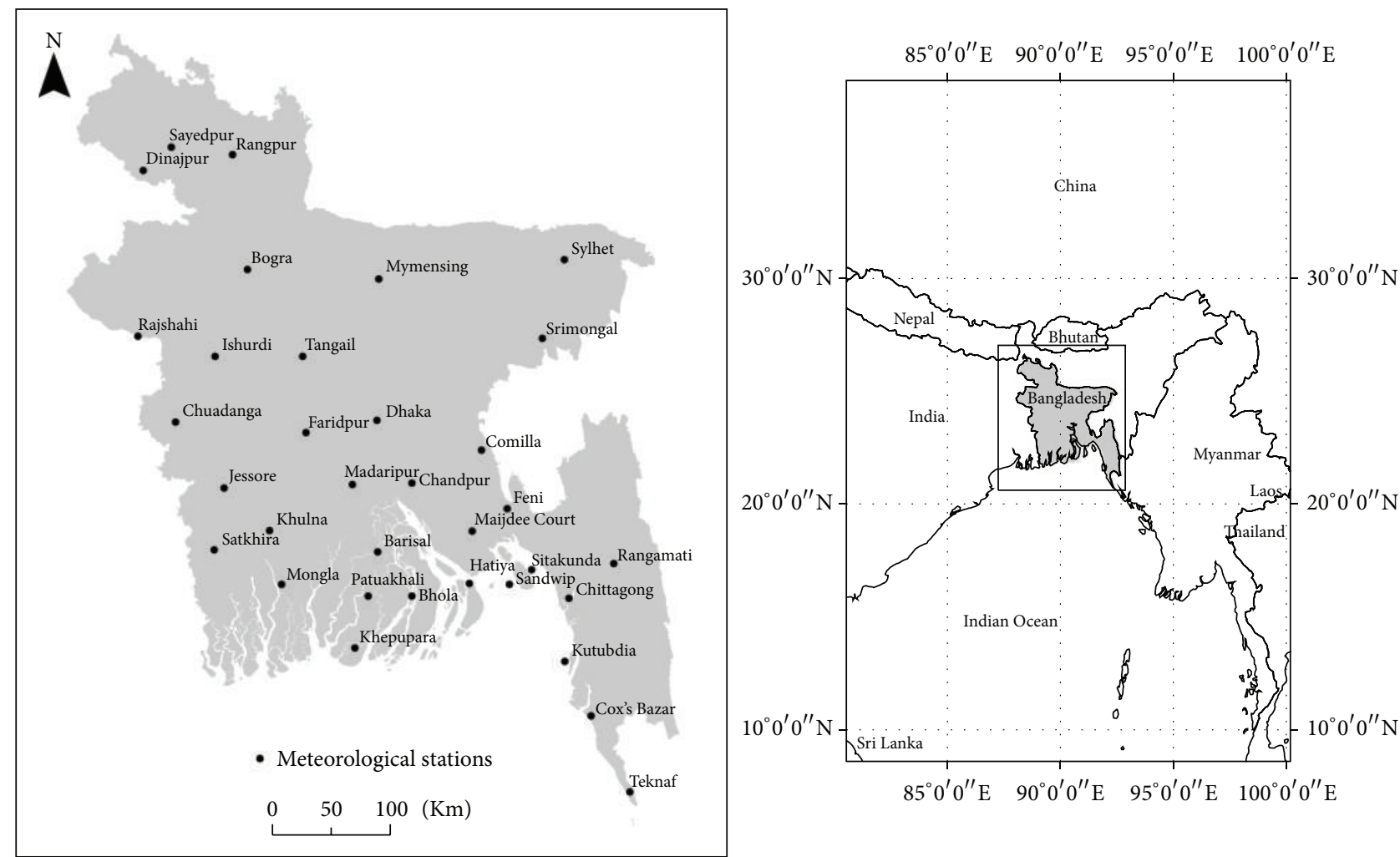

Figure 1: Maps of the part of Southeast Asia with the location of Bangladesh and neighboring countries and Bangladesh with the location of 34 meteorological stations for which the data is available in 2007. In general, the time series used for these stations is 1948-2007.

long-term droughts and famine in this region. The southern coastal regions in contrast experience the lowest moderate temperature in summer [21]. These study results provide the evidences of spatial trends in temperature and precipitation phenomena over the country. Therefore, a two-dimensional spatial trend analysis of the temperature and precipitation indices, which represent the seasonal climatic phenomena in Bangladesh, and the temporal pattern analysis of the spatial trends are of utmost importance for climate change mitigation and climate resilience activities. More importantly, the analyses of the spatial trends will provide more detailed knowledge of the climate variability within the region over time. A two-dimensional spatial trend surface provides indicators (slopes), which are spatial characterizations of the climatic fields in each time step. Thus the temporal interpolation of the spatial trends brings important information on regional climatic shifts, since fields of climate anomalies, once the background climate means are removed, tend to be more spatially coherent than the raw observations themselves [812]. It is also urgent to compare between the spatial trends of precipitation and temperature indices to discover the status of vulnerability of the country and people with respect to the change in both climatic phenomena.

This study, in spite of the discussion above, attempts to provide new information on the spatial trends of the climatic phenomena in the regional scale of Bangladesh, using longterm observations of daily temperature and precipitation from 34 meteorological stations during 1948-2007. It analyses and compares between the two-dimensional spatial trends of the indices for summer maximum temperature and annual total monsoon precipitation events by fitting the twodimensional least square surfaces along latitudes and longitudes of the observation points. The annual spatial trends are further interpolated in time to analyze the temporal pattern of the spatial trends of the two indices within the extent of the study period. Two climate indices have been selected for the spatial trend analysis and comparison, which are recommended by the Joint Project Commission for Climatology/Climate Variability and Predictability (CLIVAR) and Joint WMO/IOC Technical Commission for Oceanography and Marine Meteorology Expert Team on Climate Change Detection and Indices, namely, TXx and PRCPTOT [28, 29]. In case of Bangladesh, according to the definition of the indices, TXx represents the annual summer maximum temperature, and PRCPTOT represents the annual total monsoon precipitation. The representative trend surfaces of the two indices from each decade during the study period have been presented, and the mean trend surfaces have been computed based on the mean spatial trends. Finally, the change in the regional variation of climate in Bangladesh has been analyzed, and corresponding consequences on crop production and other resources have been predicted. These analyses are very important for Bangladesh since any change in the regional scale of climate can have large impacts on the 
daily life of the population that is dependent on agriculture and threatened by devastating floods every year.

\section{Material and Methods}

2.1. Data, Tools, and Quality Control. The daily maximum temperatures and daily precipitation data obtained from the 34 meteorological stations across Bangladesh for the period between 1948 and 2007 have been utilized in this study. The data are not available from all stations in every year because all the stations did not start working and providing data at the same time [30]. On one hand, temperature data from 10 stations are available for 1948 which gradually increases to the data from 34 meteorological stations by 2007. On the other hand, precipitation data from 8 stations are available for 1948 which gradually increases to the data from 32 meteorological stations by 2007. Therefore, the 1948-2007 period has been chosen because it characterizes a long-term dataset for each station and fosters the annual spatial trend analysis. The station locations are shown in Figure 1, and their latitudes, longitudes, and altitudes are provided in Table 1. The dataset is provided by the Bangladesh Meteorological Department (BMD), which is the authorized government organization for all meteorological activities in the country [30].

The open source statistical software "RStudio" [31] with its particular packages, "spacetime," "intamap," "fields," "gstat," "scatterplot3d," "maptools," and "sm," has been used in this study for the climate indices computation, their spatial trend analyses, temporal interpolation and visualization. The Rmodule especially designed for climate indices computation and data quality control entitled "RClimdex" [32] has been adapted for this study. ASCII format for raster grids and CSV or TXT formats for the temperature and precipitation records have been used as the input data file as $R$ requires. The temperature units are degrees Celsius $\left({ }^{\circ} \mathrm{C}\right)$, and the precipitation units are millimeters $(\mathrm{mm})$.

An exhaustive data quality control has been conducted being aware of the fact that indices are sensitive to changes in station location, exposure, equipment, and observer practice [32]. The procedures that have been performed are: (1) replacing all missing values to an internal format that the software recognizes, that is, NA, not available, and (2) replacing all unreasonable values into $\mathrm{NA}$, which include (a) daily maximum temperature more than $60^{\circ} \mathrm{C}$ (only one observation has been identified which is unlikely for a subtropical climate like Bangladesh [14-16]; this has been considered as a systematic bias) and (b) daily precipitation less than zero. The count of NA values for each month was also recorded to ensure rational computation of the climate indices based on their definition $[32,33]$. This reduces any systematic bias caused by changes of precipitation gauges and temperature measurement instruments over the 60 years.

\subsection{Methodological Framework}

2.2.1. Indices for Summer Temperature and Monsoon Precipitation. TXx refers to the yearly maximum value of the daily maximum temperature $[28,34]$. Bangladesh has a clearly defined summer season that is recognized in MarchJune every year $[14,15]$. The maximum temperature of every year is observed during this summer season which characterizes the magnitude of corresponding summer. Therefore, TXx for Bangladesh stands for the maximum summer temperature recorded in the country, and it is the most representative of the summer temperature anomaly. The formula for calculating TXx is if TXx is the daily maximum temperatures in period $j$, then the maximum daily temperature for each period is as (1) [28]. The period $j$ is set to March-June for each year.

Therefore,

$$
\mathrm{TXx}_{j}=\max \left(\mathrm{TXx}_{j}\right)
$$

Considering that a single observation can be affected by a particular synoptic episode over a limited area and may not represent the actual overall warming or cooling tendency in that year; the top $20 \% \mathrm{TXx}$ over the summer period have been averaged for each station.

PRCPTOT refers to the annual total precipitation in wet days $[28,35]$. Bangladesh has clearly defined wet days in each year, this particular precipitation phenomenon is known as "Monsoon" and is present in June-September every year [7, 14, 36-38]. Therefore, PRCPTOT for Bangladesh stands for the total monsoon precipitation in each year and it is the most representative of the mean precipitation anomaly. The formula for calculating PRCPTOT is if $\mathrm{RR}_{i j}$ is the daily precipitation amount on day $i$ in wet period $j$ and if $l$ represents the number of days in $j$, then PRCPTOT is as (2) [28]. The period $j$ for PRCPTOT calculation is set to JuneSeptember for each year.

Hence,

$$
\operatorname{PRCPTOT}_{j}=\sum_{i=1}^{l} \mathrm{RR}_{i j} .
$$

These two indices have been computed from the available temperature and precipitation data for each year of 19482007 and for each station. Following the monthly NA count for the observations, the threshold has been set to $80 \%$ for the designated periods. Therefore the indices have only been calculated when $80 \%$ of the daily observations of maximum temperature and precipitation are available for the summer (March-June) and monsoon (June-September), respectively; otherwise the indices have been set to NA. Table 1 demonstrates the producible TXx and PRCPTOT records within the temporal extent of the study with the available temperature and precipitation data.

2.2.2. Spatial Trends of the Indices. The resulting series of the summer temperature and monsoon precipitation indices have been analyzed through spatial trends. Significant correlations of the computed indices to the latitudes and longitudes justify the spatial trend analysis (will be discussed in Section 3). The spatial trend analysis includes fitting a two-dimensional least square surface along latitudes and longitudes as (3). 
Consider,

$$
B=Y+P_{1} A_{1}+P_{2} A_{2}
$$

where $B$ represents the least square value of the particular index and $A_{1}$ and $A_{2}$ represent the two independent variables-longitude and latitude in two different dimensions-along which the least square trend surface is computed. A third dimension, altitude, could have been included, but the correlation of the indices to altitude has resulted insignificant. This is an artifact of the altitudes of the stations being less than $50 \mathrm{~m}$. The intercept $Y$ and slopes $P_{1}$ and $P_{2}$ of the annual spatial trends of the climate indices have been calculated based on the fitted least square surfaces according to

$$
\begin{gathered}
Y=B-P_{1} A_{1}-P_{2} A_{2}, \\
P_{i}=\frac{\sum\left(A_{i}-A_{\mathrm{av}}\right)\left(B_{i}-B_{\mathrm{av}}\right)}{\sum\left(A_{i}-A_{\mathrm{av}}\right)^{2}},
\end{gathered}
$$

where $A_{\mathrm{av}}$ and $B_{\mathrm{av}}$ indicate the average value of the $A$ and $B$, respectively. The intercept $y$ calculates the point at which the least square surface of a particular index intersects the index axis by using existing index values, latitude values and longitude values. It determines the index surface value when there is no spatial trend along the latitude and longitude. The slope values $P_{1}$ and $P_{2}$ represent the trends of the index along latitude and longitude, respectively. Trends are obtained for each index at 60 years, the statistical significance $p$ of the trends were assessed through applying the F-statistics [39], and the number of degrees of freedom was obtained based on the length of the dataset, that is, 8-34 for the varying number of spatial data points $[32,39]$. According to the F-statistics, for 8-34 degrees of freedom, statistically significant trends at the $90 \%(0.05<p \leq 0.1), 95 \%(0.01<p \leq 0.05)$, and $99 \%$ $(p \leq 0.01)$ confidence levels have been identified.

2.2.3. Temporal Interpolation of the Spatial Trends. The spatial trends of the indices have been interpolated in time to analyze the temporal change in regional pattern of climate variability. Thin plate smoothing spline method described by Hutchinson and Hancock $[40,41]$ has been applied to interpolate the spatial trend values within the temporal extent of 1948-2007. The spatial trends of the indices are considered as observations $\left(z_{i}, x_{1 i}, x_{2 i}, \ldots, x_{d i}\right)$ measuring a dependent variable $z$ and predictor variables $x_{1}, x_{2}, \ldots, x_{D}$ which are included in a set of time domain $D$. If $z$ has both continuous long-term variation as well as discontinuous and random short-term variation, then the data model can be expressed as (5)

$$
z_{i}=g\left(x_{1}, x_{2}, \ldots, x_{D}\right)+\epsilon_{i} \quad(i=1, \ldots, n),
$$

where $n$ is the number of data observations, $g$ is a slowly varying continuous function, and $\epsilon_{i}$ is the realization of a random variable $\epsilon$. The function $g$ represents the temporarily continuous long range variation in the process measured by $z_{i}$. The errors of $\epsilon_{i}$ are assumed to be independent with mean zero and variance $\sigma^{2}$. The thin plate smoothing spline predicts the process $g$ in (5) by a suitably continuous function $f$ that is able to separate the continuous signal $g$ from the discontinuous noise $\epsilon_{i}$. This function can be estimated by minimizing

$$
\frac{1}{n} \sum_{i=1}^{n}\left(z_{i}-f_{i}\right)^{2}+\lambda J_{m}^{D}(f)
$$

over functions $f \in X$, where $X$ is a time function whose partial derivatives of total order $m$ are in $L^{2}\left(E^{d}\right)$. The $f_{i}$ are values of the fitted function at the $i$ th measurement, $\lambda$ is a fixed smoothing parameter, and $J_{m}^{D}(f)$ is a measure of the roughness of the function $f$ in terms of $m$ th order partial derivatives. The thin plate smoothing spline represents a smooth gradual increase or decrease of the spatial trend values along the time series.

\section{Results}

3.1. Spatial Trends of the Temperature and Precipitation Indices. The computed values of the climate indices-TXx and PRCPTOT-vary between $30^{\circ} \mathrm{C}-46^{\circ} \mathrm{C}$ and $750 \mathrm{~mm}-$ $4516 \mathrm{~mm}$, respectively. Figure 2 represents the distribution of the computed TXx and PRCPTOT values at every station in every year. A general spatial trend of the indices over the study area during the study period can be observed. On one hand, in almost all the years, the maximum TXx values ranging between $38^{\circ} \mathrm{C}$ and $46^{\circ} \mathrm{C}$ are observed at the stations situated in the north-western, whereas the minimum $\mathrm{TXx}$ values ranging between $30^{\circ} \mathrm{C}$ and $32^{\circ} \mathrm{C}$ are observed at the stations situated in the south-eastern parts of the country. There is a gradual increase in the TXx values from the southeast to the north-west of the country in all years which provides evidence that spatial trend in the TXx index exists in the same direction. On the other hand, the calculated maximum PRCPTOT values which range $2000 \mathrm{~mm}-4500 \mathrm{~mm}$ are observed at the stations situated in the south-eastern and the minimum PRCPTOT values which range $750 \mathrm{~mm}-1500 \mathrm{~mm}$ at the stations situated in the north-western parts of the country. There is also a gradual increase in the PRCPTOT values from the north-west to the south-east of the country out of the precipitation noise in all the years, which clearly indicates a spatial trend in the PRCPTOT index from the north-west to south-east.

Moreover, the calculated correlation-coefficients of the TXx with the stations' latitudes and longitudes are 0.34 and -0.52 , respectively, which indicates that the spatial dependence of the index is more dominant in the westeast direction than in the south-north direction. Similarly, the correlation-coefficients of PRCPTOT with the stations' latitudes and longitudes are -0.42 and 0.55 , respectively, which indicates that the spatial dependence of the index is more dominant in the east-west direction than in the northsouth direction. In parallel, the correlation of both TXx and PRCPTOT with altitude has also been computed, which are found insignificant, and therefore the decision is made that altitude does not affect any of the indices in their spatial dependence. 
TABLE 2: Yearly spatial trends and intercepts of the indices for the temperature and precipitation over Bangladesh during $1948-2007$.

\begin{tabular}{|c|c|c|c|c|c|c|}
\hline \multirow[b]{2}{*}{ Years } & \multicolumn{3}{|c|}{ TXx } & \multicolumn{3}{|c|}{ PRCPTOT } \\
\hline & $\begin{array}{c}\text { Intercept } \\
\left({ }^{\circ} \mathrm{C}\right)\end{array}$ & $\begin{array}{l}\text { Trend-longitude } \\
\left({ }^{\circ} \mathrm{C} \mathrm{dd}^{-1}\right)\end{array}$ & $\begin{array}{l}\text { Trend-latitude } \\
\left({ }^{\circ} \mathrm{C} \mathrm{dd}^{-1}\right)\end{array}$ & $\begin{array}{l}\text { Intercept } \\
(\mathrm{mm})\end{array}$ & $\begin{array}{l}\text { Trend-longitude } \\
\left(\mathrm{mm} \mathrm{dd}^{-1}\right)\end{array}$ & $\begin{array}{c}\text { Trend-latitude } \\
\left(\mathrm{mm} \mathrm{dd}^{-1}\right)\end{array}$ \\
\hline 1948 & 103.8016 & $-0.7537^{* * *}$ & 0.0625 & -29088.7 & 376.9 & -143 \\
\hline 1949 & 68.3107 & $-0.2333^{* * *}$ & -0.5117 & -23148.8 & 333.5 & $-223.8^{* *}$ \\
\hline 1950 & 73.4924 & -0.4364 & 0.1456 & -4596.5 & 195.8 & $-483.2^{*}$ \\
\hline 1951 & 125.5522 & $-0.9277^{* * *}$ & -0.2017 & -29394.81 & 350.62 & -38.25 \\
\hline 1952 & 17.360687 & -0.007369 & 0.911620 & -15961.6 & 238.2 & $-161.9^{* * *}$ \\
\hline 1953 & 78.5432 & $-0.5917^{* *}$ & $0.4979^{*}$ & -15137.5 & 245 & $-221.8^{*}$ \\
\hline 1954 & 161.1209 & -1.5983 & 0.9162 & -10420.3 & 197.2 & $-233.4^{* *}$ \\
\hline 1955 & 198.2763 & $-1.6914^{* *}$ & -0.3202 & -37526.6 & $382.6^{* * *}$ & 196.2 \\
\hline 1956 & 222.6913 & $-1.9503^{*}$ & -0.2872 & -29687.48 & $348.799^{*}$ & $5.367^{* *}$ \\
\hline 1957 & 144.29750 & -1.14795 & -0.09892 & -17896.22 & 206.47 & 21.77 \\
\hline 1958 & 161.4466 & $-1.5386^{*}$ & $0.7119^{*}$ & -30510.06 & $336.95^{* *}$ & 51.96 \\
\hline 1959 & 195.1917 & $-1.7594^{*}$ & $0.1079^{* *}$ & -23323.1 & $288.6^{* * *}$ & $-45.7^{* * *}$ \\
\hline 1960 & 25.3299 & -0.1297 & $1.1547^{*}$ & -2568.8 & 93.29 & -178.83 \\
\hline 1961 & 179.60017 & -1.56272 & $0.04544^{* *}$ & -18565.7 & $323.8^{* * *}$ & $-383.1^{*}$ \\
\hline 1962 & 137.363 & -1.240 & 0.557 & -31848.51 & $360.01^{*}$ & $29.38^{* *}$ \\
\hline 1963 & 165.88467 & $-1.42300^{*}$ & 0.03316 & -33962.83 & $380.80^{*}$ & $45.02^{* * *}$ \\
\hline 1964 & 159.5418 & -1.2443 & -0.4053 & -44464 & $465.7^{*}$ & 169.9 \\
\hline 1965 & 165.0051 & $-1.5313^{*}$ & $0.5039^{*}$ & -25449.01 & $316.44^{* * *}$ & -54.99 \\
\hline 1966 & 101.2386 & -0.8977 & $0.7845^{* *}$ & -38080.81 & $451.77^{*}$ & $-49.72^{*}$ \\
\hline 1967 & -4.64955 & 0.42860 & 0.06532 & -31650.7 & $396.2^{* *}$ & $-110.6^{* *}$ \\
\hline 1968 & 104.3254 & $-0.9106^{* *}$ & $0.6626^{*}$ & -47098.03 & $534.94^{*}$ & $20.13^{* *}$ \\
\hline 1969 & 192.1136 & $-1.6794^{*}$ & -0.1081 & -27956.9 & $369.6^{* *}$ & $-157.6^{* *}$ \\
\hline 1970 & 162.1099 & $-1.5462^{*}$ & $0.6616^{*}$ & -35447.65 & $395.05^{*}$ & 59.78 \\
\hline 1971 & 30.6352 & -0.0764 & $0.5080^{* *}$ & -7052.3 & 200.9 & -402 \\
\hline 1972 & 173.6323 & $-1.6547^{*}$ & $0.5991^{*}$ & -25619.05 & $291.13^{* *}$ & 22.49 \\
\hline 1973 & 156.567 & -1.598 & 1.098 & -5934.26 & 96.83 & -59.97 \\
\hline 1974 & 160.5881 & -1.4366 & 0.2716 & -34744.4 & $441.6^{* *}$ & $-145.7^{* *}$ \\
\hline 1975 & 168.8692 & $-1.6862^{*}$ & $0.9412^{*}$ & -11241.5 & 194.5 & $-215.0^{*}$ \\
\hline 1976 & 254.41470 & -2.39811 & $0.04196^{* * *}$ & -47562.3 & $490.9^{*}$ & 210.3 \\
\hline 1977 & 112.5683 & -0.9820 & 0.5351 & -10141.5 & 188.2 & $-228.3^{*}$ \\
\hline 1978 & 72.3471 & $-0.5746^{* * *}$ & 0.7181 & -16762.9 & 240 & $-143.4^{* *}$ \\
\hline 1979 & 215.8671 & -2.0008 & 0.1767 & -10600.1 & 102.9 & 121.4 \\
\hline 1980 & 176.1498 & -1.5847 & $0.2362^{*}$ & -2900.498 & 46.222 & 1.344 \\
\hline 1981 & 98.0694 & -0.7403 & 0.2140 & -21583.3 & $296.3^{* *}$ & $-155.8^{*}$ \\
\hline 1982 & 108.0663 & $-0.8164^{*}$ & $0.1579^{*}$ & -30514.4 & $413.8^{* *}$ & -215.5 \\
\hline 1983 & 123.6575 & -0.9997 & $0.1674^{*}$ & -35315.24 & $411.807^{*}$ & $-8.191^{* *}$ \\
\hline 1984 & 122.0941 & -1.0714 & 0.5498 & -12669.5 & 193.4 & $-115.2^{* * *}$ \\
\hline 1985 & 198.261425 & -1.775920 & $-0.007286^{*}$ & -22804.02 & $283.93^{* *}$ & $-55.01^{* *}$ \\
\hline 1986 & 159.2983 & -1.4260 & 0.3307 & -12779.4 & $195.0^{* *}$ & -134.3 \\
\hline 1987 & 200.0741 & -1.7634 & -0.1075 & -33677.72 & $401.94^{* *}$ & $-23.91^{* *}$ \\
\hline 1988 & 156.13074 & -1.33725 & $0.08981^{*}$ & -44693.04 & 502.69 & $46.42^{* *}$ \\
\hline 1989 & 195.5940 & -1.8502 & 0.4334 & -49170.7 & 517.8 & 161.7 \\
\hline 1990 & 90.2426 & $-0.6675^{* *}$ & $0.2680^{*}$ & -25302.23 & $312.52^{*}$ & $-58.26^{*}$ \\
\hline 1991 & 108.60294 & $-0.81179^{*}$ & $0.08409^{*}$ & -29569.9 & 381.8 & -129.7 \\
\hline 1992 & 166.5412 & -1.4896 & 0.2765 & -20994.75 & $257.81^{*}$ & $-40.51^{*}$ \\
\hline 1993 & 100.70048 & $-0.72120^{*}$ & $0.03924^{* *}$ & -45265.5 & 478.7 & 163.3 \\
\hline
\end{tabular}


TABLe 2: Continued.

\begin{tabular}{|c|c|c|c|c|c|c|}
\hline \multirow[b]{2}{*}{ Years } & \multicolumn{3}{|c|}{ TXx } & \multicolumn{3}{|c|}{ PRCPTOT } \\
\hline & $\begin{array}{l}\text { Intercept } \\
\left({ }^{\circ} \mathrm{C}\right)\end{array}$ & $\begin{array}{l}\text { Trend-longitude } \\
\left({ }^{\circ} \mathrm{C} \mathrm{dd}^{-1}\right)\end{array}$ & $\begin{array}{l}\text { Trend-latitude } \\
\qquad\left({ }^{\circ} \mathrm{C} \mathrm{dd}^{-1}\right)\end{array}$ & $\begin{array}{l}\text { Intercept } \\
(\mathrm{mm})\end{array}$ & $\begin{array}{l}\text { Trend-longitude } \\
\quad\left(\mathrm{mm} \mathrm{dd}^{-1}\right)\end{array}$ & $\begin{array}{l}\text { Trend-latitude } \\
\left(\mathrm{mm} \mathrm{dd}^{-1}\right)\end{array}$ \\
\hline 1994 & 151.8259 & -1.3179 & 0.2347 & -14942.1 & $243.8^{* *}$ & -246.7 \\
\hline 1995 & 183.0792 & -1.5888 & -0.0298 & -24787.1 & $266.1^{* *}$ & 107.5 \\
\hline 1996 & 155.78969 & -1.32219 & 0.07176 & -18987.7 & $258.6^{* *}$ & -119.9 \\
\hline 1997 & 102.0541 & -0.7728 & 0.2109 & -29502.38 & 355.16 & -34.13 \\
\hline 1998 & 127.94642 & -1.00331 & $0.02429^{*}$ & -41110.5 & 480.8 & $-19.3^{*}$ \\
\hline 1999 & 97.3587 & $-0.7064^{* *}$ & $0.1831^{* *}$ & -16258.9 & $247.4^{* *}$ & -176.6 \\
\hline 2000 & 97.24909 & -0.65306 & $-0.04446^{* *}$ & -31375.2 & $399.6^{*}$ & -135.3 \\
\hline 2001 & 83.09171 & $-0.50906^{* *}$ & $0.03273^{* * *}$ & -23168.2 & $324.1^{* *}$ & $-188.6^{*}$ \\
\hline 2002 & 160.745 & -1.208 & -0.618 & -17521.24 & $219.80^{* * *}$ & $-18.59^{* * *}$ \\
\hline 2003 & 247.777 & $-2.013^{* *}$ & -1.180 & -31519.6 & $396.3^{*}$ & -116.5 \\
\hline 2004 & 1.8089 & 0.1002 & $1.1987^{* * *}$ & -26830.19 & $330.83^{*}$ & $-42.72^{*}$ \\
\hline 2005 & 165.6108 & -1.3359 & $-0.2931^{* *}$ & -19607.49 & $260.30^{* *}$ & $-96.51^{*}$ \\
\hline 2006 & 104.1688 & $-0.6952^{*}$ & -0.1426 & -11883.7 & $205.3^{* *}$ & -218.5 \\
\hline 2007 & 121.1362 & -0.9814 & 0.2382 & -29451 & 357.95 & -40.97 \\
\hline
\end{tabular}

${ }^{*} 99 \%$ level of significance $(p \leq 0.01) ;{ }^{* *} 95 \%$ level of significance $(0.01<p \leq 0.05) ;{ }^{* * *} 90 \%$ level of significance $(0.05<p \leq 0.1)$; dd: decimal degree.

These significant observations lead to the detailed analyses of the spatial trends in the climate indices. Representative examples of the approaches are presented in Figure 3. Since space is two-dimensional, the spatial trend analysis of the indices requires fitting a two-dimensional least square surface along latitudes and longitudes, which have been represented by the dotted regular grids. Least square surface of TXx computed for 2007 represents the increasing spatial trend with the increasing latitudes and decreasing longitudes, whereas the least square surface of PRCPTOT for 2007 represents the increasing spatial trend with the decreasing latitudes and increasing longitudes (Figure 3). The corresponding trend (slope) values with the intercepts represent the attitudes of the spatial trends.

Similar approach, as presented in Figure 3, has been applied to analyze the spatial trends of the two indices in every year of 1948-2007. The intercepts and the spatial trend values of the indices with their F-statistical significances at the three particular confidence levels are presented in Table 2. As observed in Figure 2, in most of the years, TXx shows a spatial trend increasing along latitudes and decreasing along longitudes, whereas PRCPTOT shows a spatial trend increasing along longitudes and decreasing along latitudes. Statistically significant spatial trend values have been resulted which represents a significant two-dimensional spatial trend in the climate variability over Bangladesh in regional scale.

An in-depth analysis has been performed on the obtained spatial trend values from Table 2. In spite of the F-statistical significance, as presented in Figure 4(a), on an average 22.92\% of the spatial trend values show statistical significance at 99\% confidence level. Another $18.75 \%$ and $7.08 \%$ of the spatial trend values on average show statistical significance at $95 \%$ and $90 \%$ confidence levels, respectively. Therefore $48.75 \%$ of the spatial trend values on average show statistical significance at $90 \%$ or more than $90 \%$ confidence level, which represents that the spatial trends in the indices and thereby the regional climate variability over years are very significant in Bangladesh. In this circumstance, some parts of Bangladesh represent more vulnerability due to climate change than the others.

As presented in Figure 4(b), the comparison of the relative values of the spatial trends depicts that, in $75 \%$ of the years, TXx shows an increasing trend along latitudes and, in around $90 \%$ of the years, the spatial trends of TXx along latitudes are lower than the spatial trends of TXx along longitudes. In contrast, in around $96.67 \%$ of the years, TXx shows a decreasing spatial trend along longitudes, when around $90 \%$ of the spatial trends of TXx along longitudes are higher than the ones along latitudes. These results clearly illustrate that the spatial trend of TXx in Bangladesh increases along latitudes and decreases along longitudes, and the trend along longitudes is more dominant than the trend along latitudes. This proves that the relative western regions of the country are experiencing the steadily higher temperatures in summers than the eastern regions of the country. The relative northern regions of the country are also experiencing the steadily higher temperatures in summers than the relative southern regions of the country, but not as severely as the western regions of the country.

Figure 4(b) also depicts that the spatial trends of PRCPTOT along latitudes in $71.67 \%$ of the years show decreasing tendency, and $83.33 \%$ of the spatial trends of PRCPTOT along latitudes are lower than the ones along longitudes. In contrast, in all the years (100\%), the spatial trends of PRCPTOT along longitudes show increasing tendency when $83.33 \%$ of the trends are higher than the ones along latitudes. This proves the fact that the spatial trend of PRCPTOT in Bangladesh increases along longitudes and decreases along latitudes, and it is more dominant along longitudes than the one along latitudes. Therefore, the relative eastern regions 
8991

8991

8991

8991

8991

8991

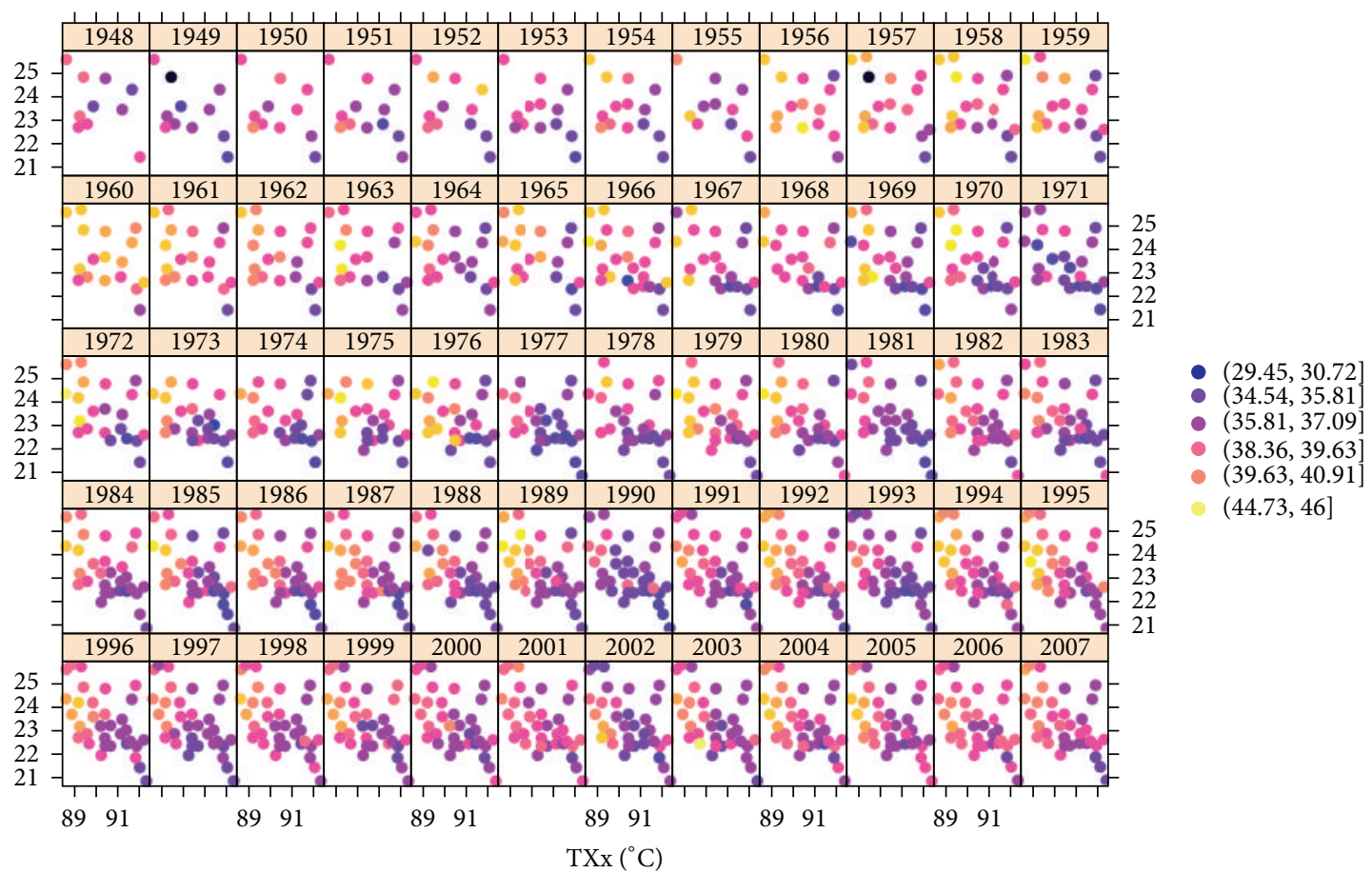

(a)

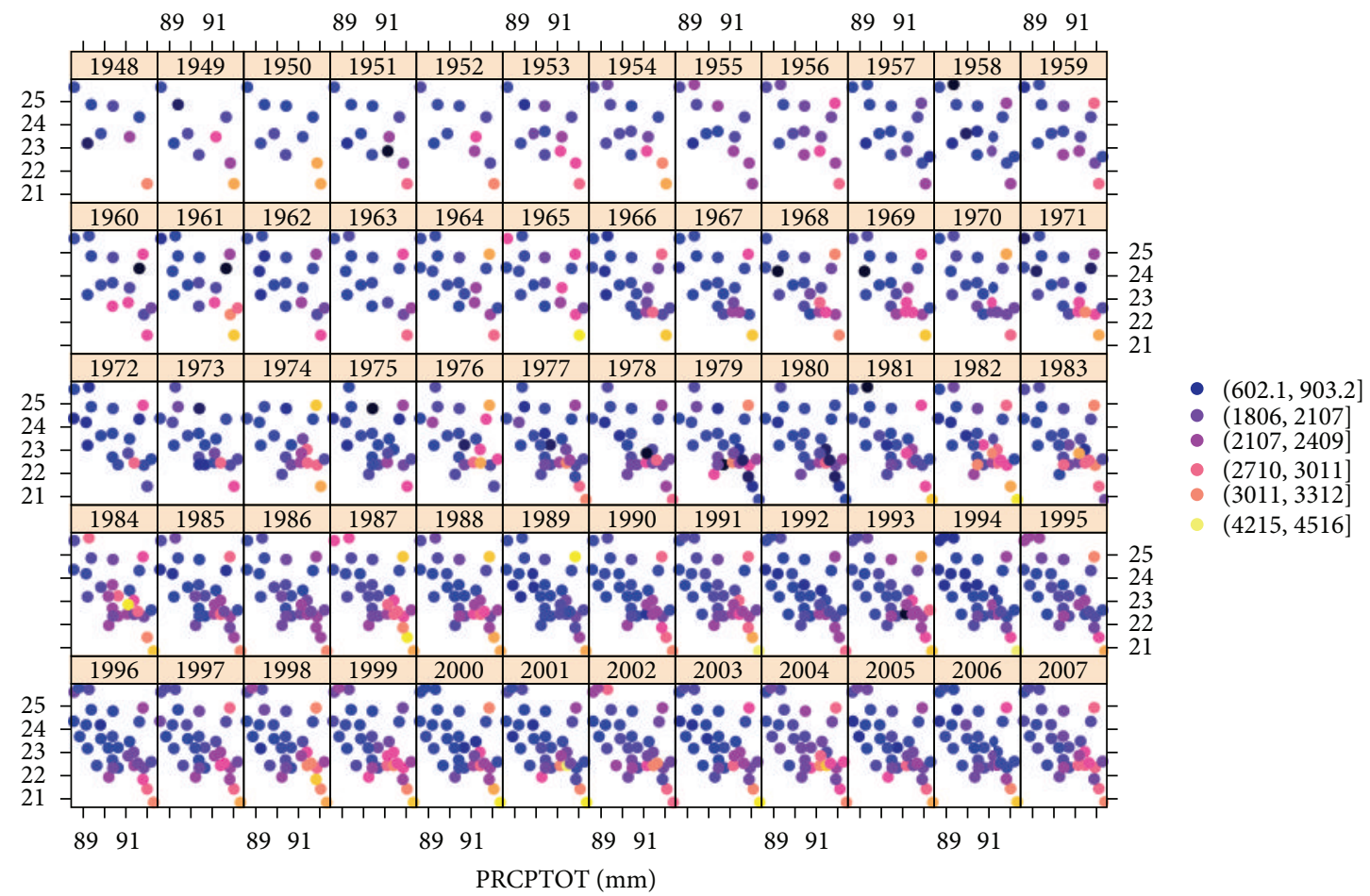

(b)

FIGURE 2: Computed (a) TXx and (b) PRCPTOT at every station and its spatial dependence over Bangladesh in every year during $1948-2007$. The computed TXx and PRCPTOT values are in ${ }^{\circ} \mathrm{C}$ and $\mathrm{mm}$, respectively. 


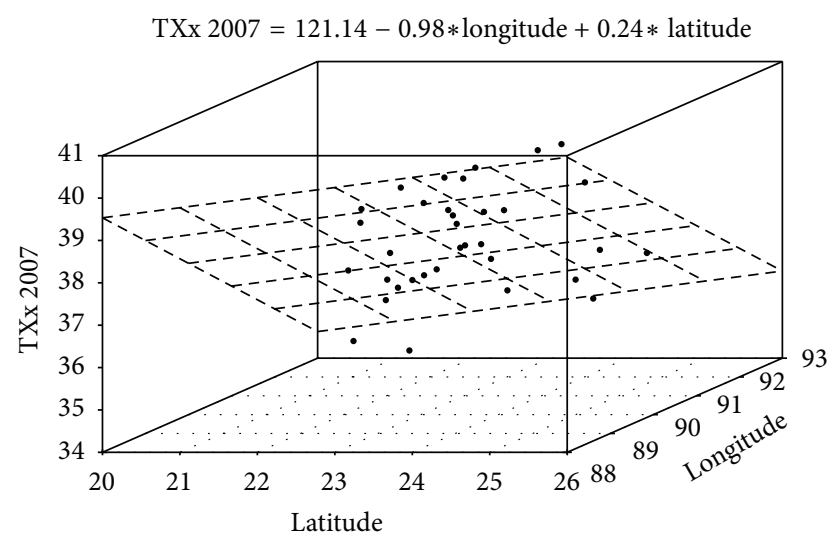

(a)

PRCPTOT $2007=-29451+357.95 *$ longitude $-40.97 *$ latitude

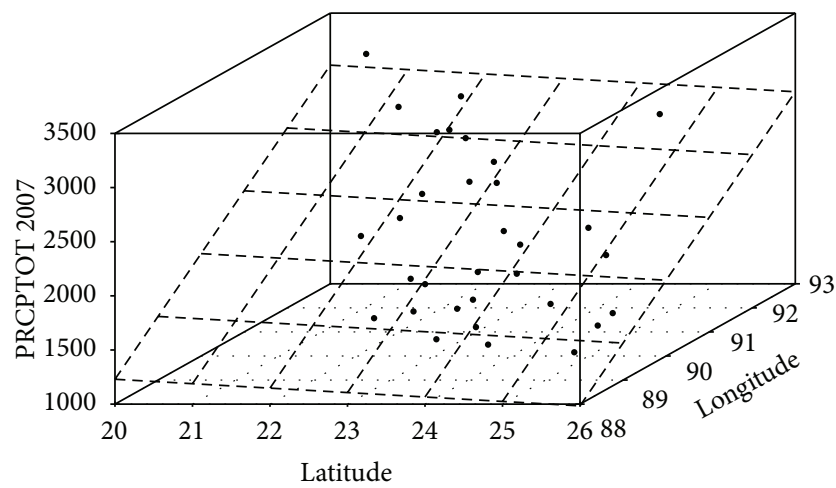

(b)

FIGURE 3: Representative least square surfaces, presented by the dotted regular grids, of (a) TXx and (b) PRCPTOT for 2007 applying corresponding intercepts and trends (slopes), fitted along the longitudes and latitudes.

of the country are experiencing steadily higher amount of monsoon precipitation than the regions situated in the relative western part of the country. In a similar fashion, the southern coastal regions of the country are also experiencing higher monsoon precipitation than the northern regions but not as higher as the eastern regions. Nevertheless, a few deviant tendencies of the spatial trends contrary to the usual tendencies have also been observed from the analyses as represented in Figure $4(\mathrm{c}) .3 .33 \%$ of the spatial trends of TXx show increasing tendencies along both latitudes and longitudes, whereas around 25\% of the trends show decreasing tendencies along both dimensions.

$28.33 \%$ of the spatial trends of PRCPTOT show increasing tendency along both latitudes and longitudes, but none of the trends shows decreasing tendency along both dimensions. After all, majority of the trends' tendencies have been considered as the mean actual spatial trends of the indices for the summer temperature and monsoon precipitation over Bangladesh during 1948-2007. The temporal period of 19482007 consists of six decades, and the least square trend surfaces of the TXx and PRCPTOT indices from each decade are presented in Figure 5. The surfaces show the indices values in regular grids calculated by fitting the least squares using the corresponding intercepts and trends (slopes) along the latitudes and longitudes as shown in Figure 3.

The decadal least square surfaces of TXx (Figure 5(a)) represent the actual dominant spatial trend from the eastern regions to the western regions of the country. The surface of 1978 represents the spatial trend from the south-east to north-west regions of the country. In 1958, the midwestern regions and north-western regions experienced the summer maximum temperature up to $50^{\circ} \mathrm{C}$. Generally, these regions experience the summer maximum temperature of $40^{\circ} \mathrm{C}-$ $45^{\circ} \mathrm{C}$. In contrast, the eastern regions of the country generally experienced the summer maximum temperature around $35^{\circ} \mathrm{C}$, though in 1968 and 1998 a few hill tracts regions of the south-eastern region experienced the maximum temperature slightly towards $40^{\circ} \mathrm{C}$ in summer time.

In contrast to the least square surfaces of TXx, the decadal least square surfaces of PRCPTOT (Figure 5(b)) represent the dominant spatial trend from the western regions to the eastern regions of the country. In 1968 and 1988 onwards, the north-eastern and south-eastern regions of the country experienced the annual monsoon precipitation of $4000 \mathrm{~mm}-$ $4500 \mathrm{~mm}$. In 1958 and 1978, the tendency is $2000 \mathrm{~mm}-$ $3000 \mathrm{~mm}$ for these regions. The northern regions of the country, violating the traditional trend, also experienced the monsoon precipitation of around $2500 \mathrm{~mm}$ in 1958, 1988, and 1998, which is basically experienced in the south and midwestern regions of the country generally. Following the typical spatial trends, the western regions of the country always experienced the monsoon precipitation less than $1500 \mathrm{~mm}$.

\subsection{Temporal Interpolation of the Spatial Trends in Climate} Indices. The spatial trend values of the TXx and PRCPTOT have been interpolated in time applying the thin plate smoothing spline with several iterations. The interpolated splines of TXX and PRCPTOT are presented in Figure 6. The number of iterations used to best fit the smoothing spline in spite of the general cross-validations is $11-13$, and the resulted smoothing parameters $(\lambda)$ range $0.71-1.02$. The interpolated splines of the spatial trends of TXx are very similar and used the same number of iterations and almost the same $\lambda$. In contrast, the interpolated splines of the spatial trends of PRCPTOT are very different which have been reflected in the different number of iterations required and the different smoothing parameters calculated. The interpolated splines depict the continuous change in the spatial trends of the indices during 1948-2007, which is very important to take into account for regional climate variability analyses of Bangladesh.

Figure 6(a) shows that almost throughout the study period, TXx represents increasing spatial trend along latitude and decreasing spatial trend along longitude. The increasing trend values (+ slopes) along latitudes have been increasing from around 0.1 to around 0.35 within 1948-1972, afterwards the increasing trend values have been decreasing and after 2000 they have been representing decreasing trends (- slopes) below 0 . In a similar way and as have been 


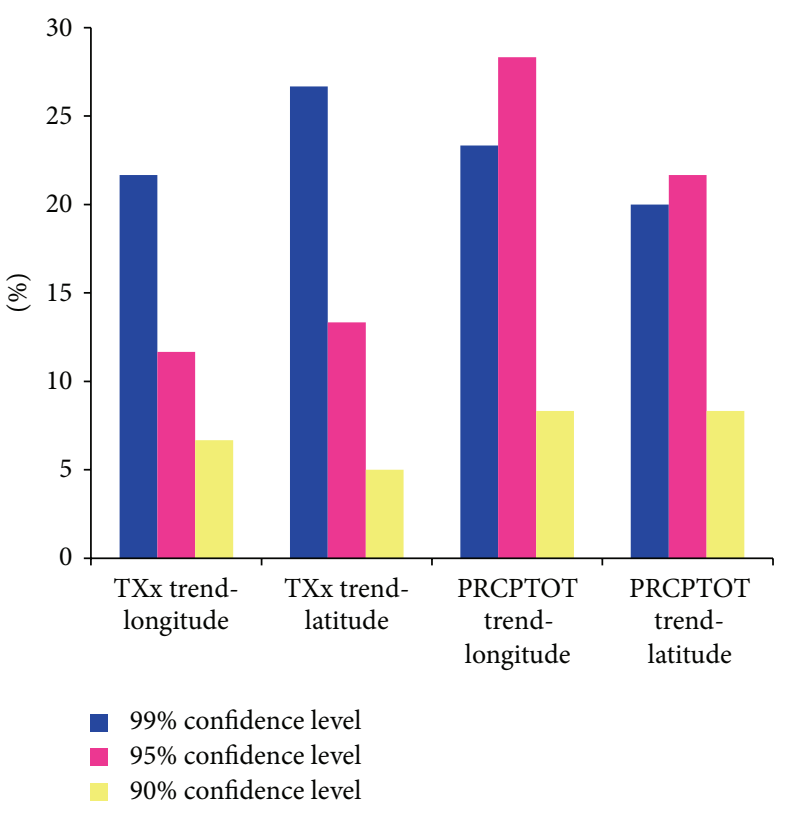

(a)

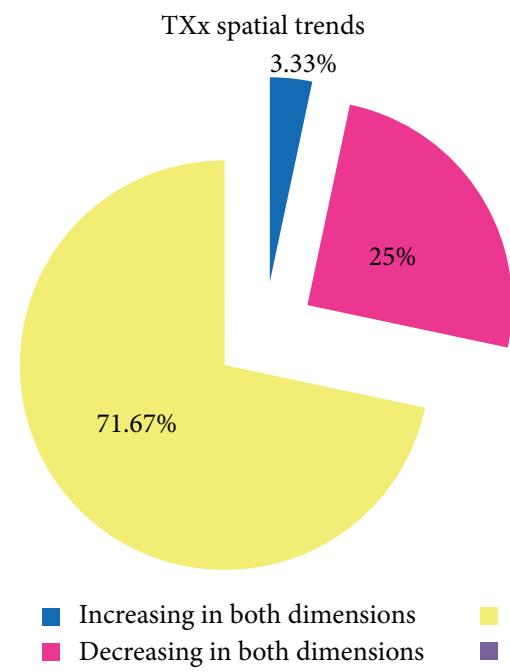

Decreasing in both dimensions

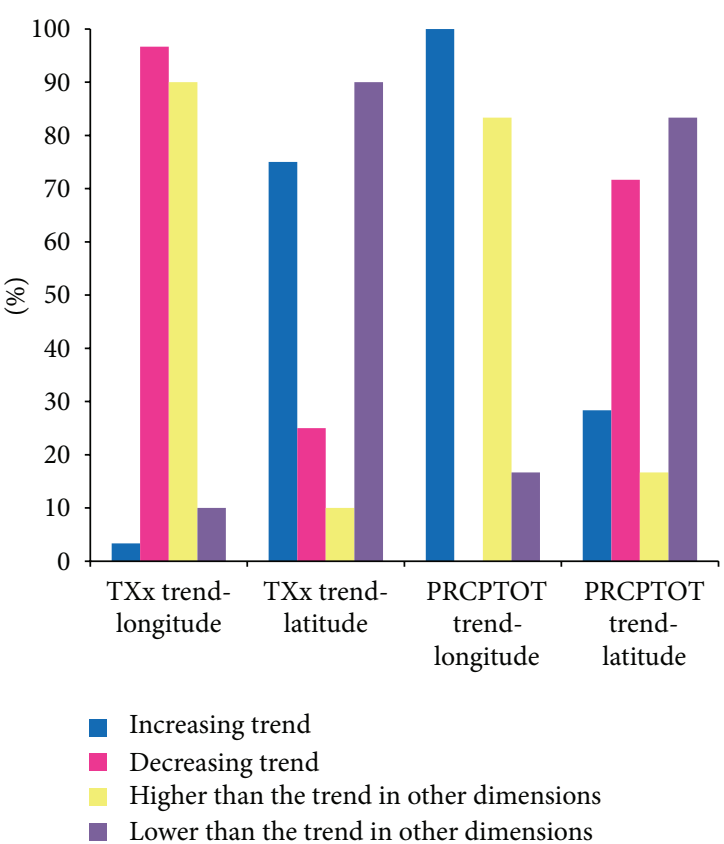

(b)

PRCPTOT spatial trends

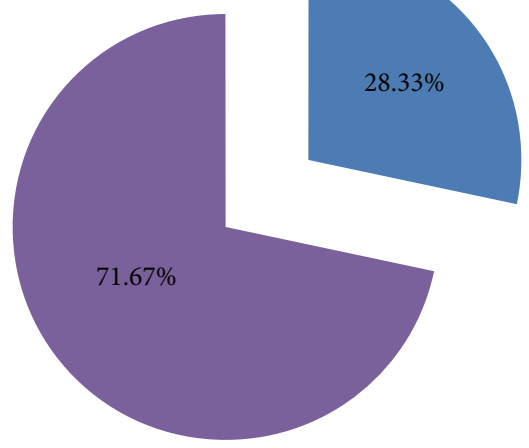

Increasing along latitude but decreasing along longitude

- Decreasing along latitude but increasing along longitude

(c)

Figure 4: Percentage of the (a) F-statistically significant spatial trends at 99\%, 95\%, and 90\% confidence levels; the (b) increasing and decreasing spatial trends of TXX and PRCPTOT and their comparative values; (c) comparative increasing and decreasing spatial trends of the TXx and PRCPTOT along latitudes and longitudes.

analyzed before, the decreasing trend values (- slopes) along longitudes have been increasing within 1948-1980 from -0.85 to -1.25 . Afterwards, the decreasing trends (- slopes) have been decreasing again till 2007. These results illustrate that the spatial variability of the annual maximum temperature in Bangladesh has been increasing from 1948 until around 1980, and since then it has been decreasing again. The tendency of the variability is from the southern and eastern regions towards the northern and western regions, though after 2000 the tendency has been changed from south-north to northsouth. If the tendency continues, there will be a complete change in the usual spatial trend of TXx over Bangladesh. This is an evidence of the regional shift of climate in Bangladesh.
Figure 6(b) depicts that throughout the study period PRCPTOT represents decreasing spatial trend along latitude and increasing spatial trend along longitude. The decreasing trend values (- slopes) along latitudes have been decreasing from around -130 to around -60 within 1948-1985, afterwards the decreasing trend values (- slopes) have been increasing until 2007, and most likely they will continue increasing. In a sharp contrast, the increasing spatial trends (+ slopes) of the PRCPTOT along longitudes display cyclic order in their change with time. In 1955-1965 and 1979-1990, the increasing trend values (+ slopes) along longitudes have been increasing from around 260 to 360 . In the remaining years, they display a decreasing tendency in a similar 
$89^{\circ} \mathrm{E} 90^{\circ} \mathrm{E} 91^{\circ} \mathrm{E} 92^{\circ} \mathrm{E} \quad 89^{\circ} \mathrm{E} 90^{\circ} \mathrm{E} 91^{\circ} \mathrm{E} 92^{\circ} \mathrm{E} \quad 89^{\circ} \mathrm{E} 90^{\circ} \mathrm{E} 91^{\circ} \mathrm{E} 92^{\circ} \mathrm{E}$

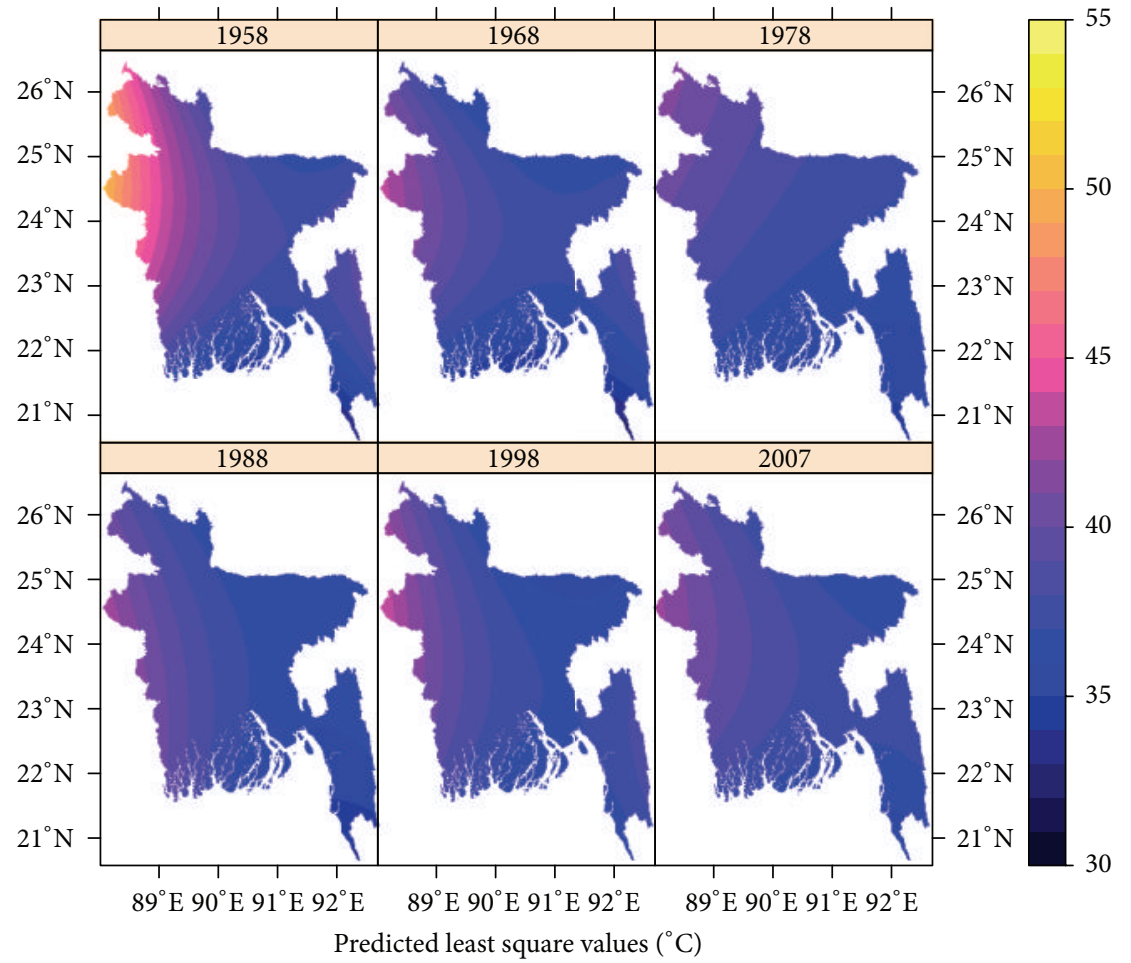

(a)

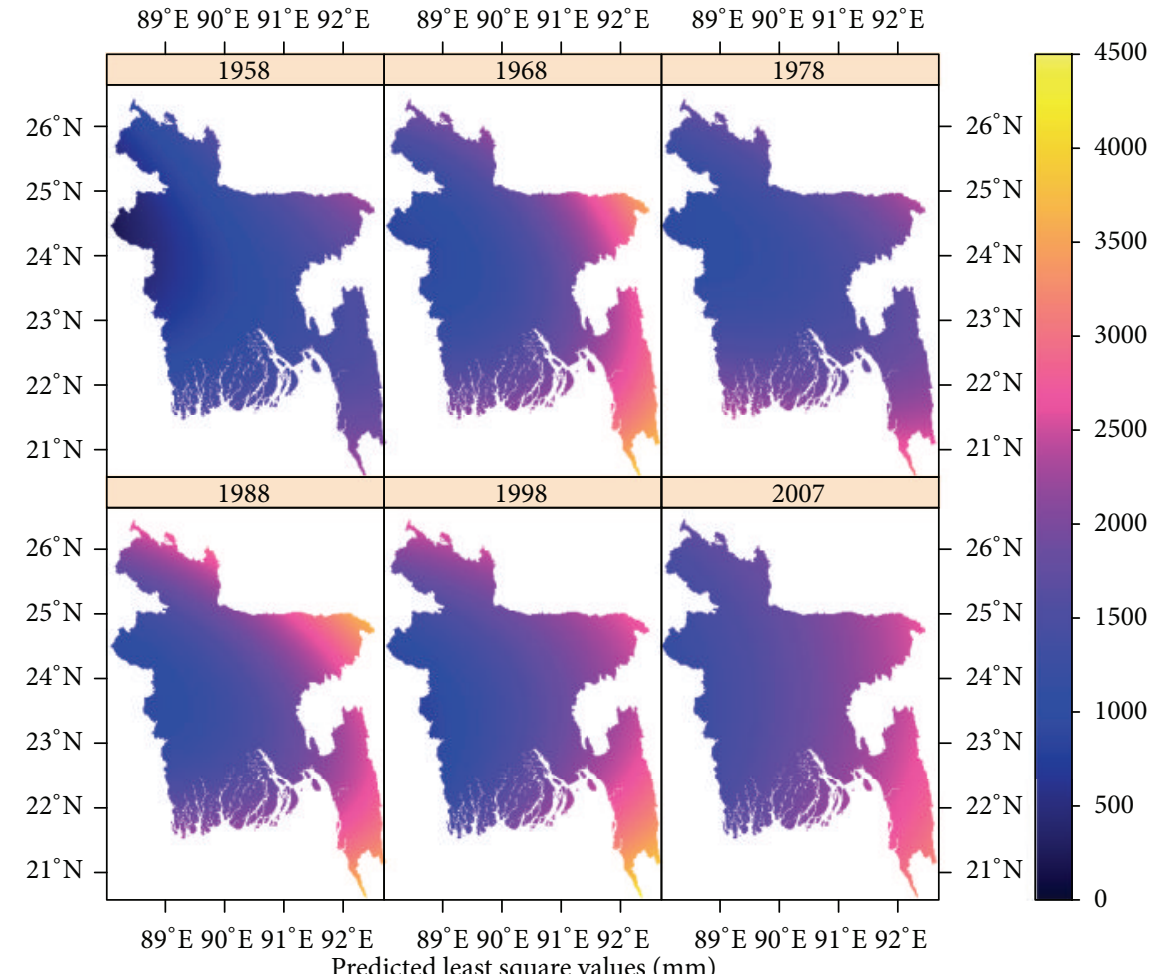

(b)

FIGURE 5: Representative trend surfaces of (a) TXx and (b) PRCPTOT from each decade, fitted using the least square approach with corresponding intercepts and trend (slope) values from Table 2. 

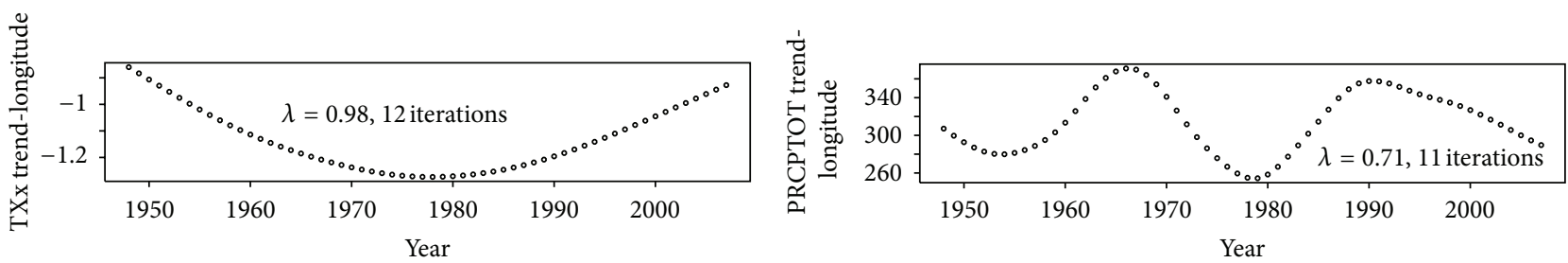

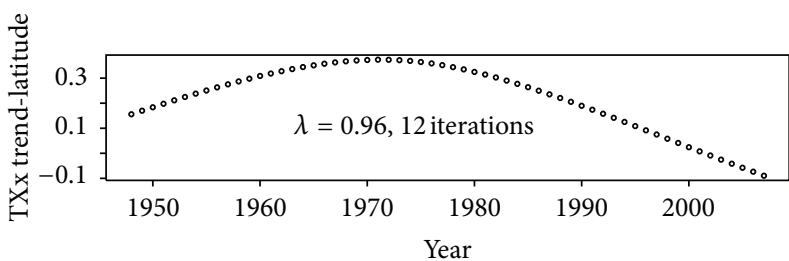

(a)

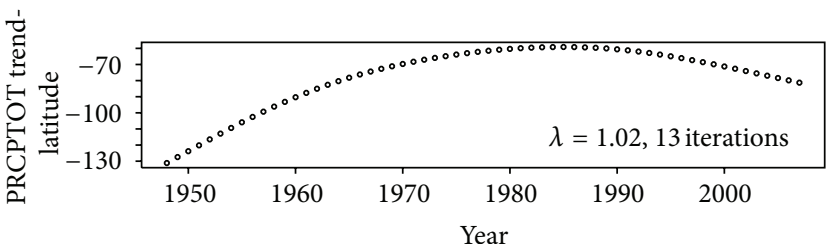

(b)

FIGURE 6: Temporally interpolated spatial trend values of (a) TXx and (b) PRCPTOT along longitudes and latitudes in the extent of 1948-2007, fitted by the thin plate smoothing spline.

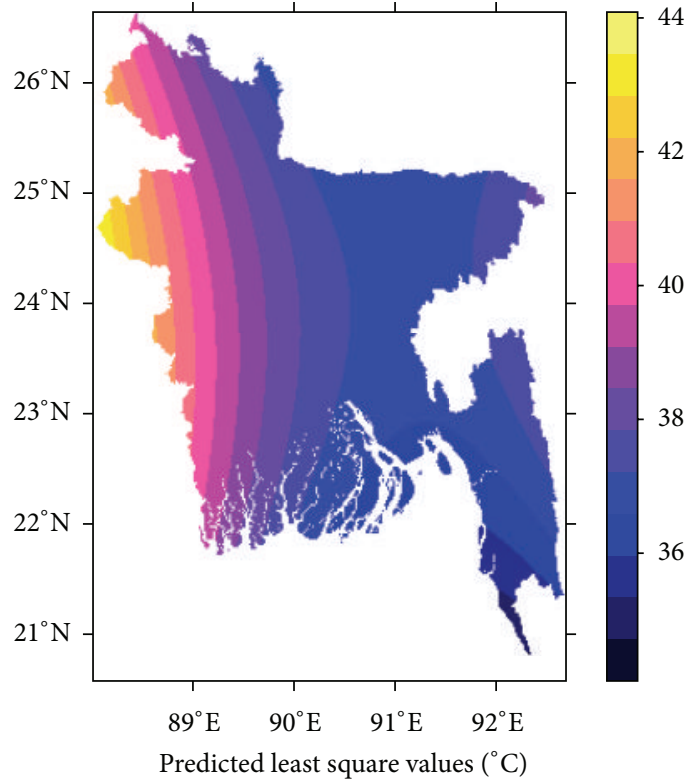

Mean trend-longitude: $-1.13^{\circ} \mathrm{Cdd}^{-1}$ Mean trend-latitude: $0.22^{\circ} \mathrm{Cdd}^{-1}$

(a)

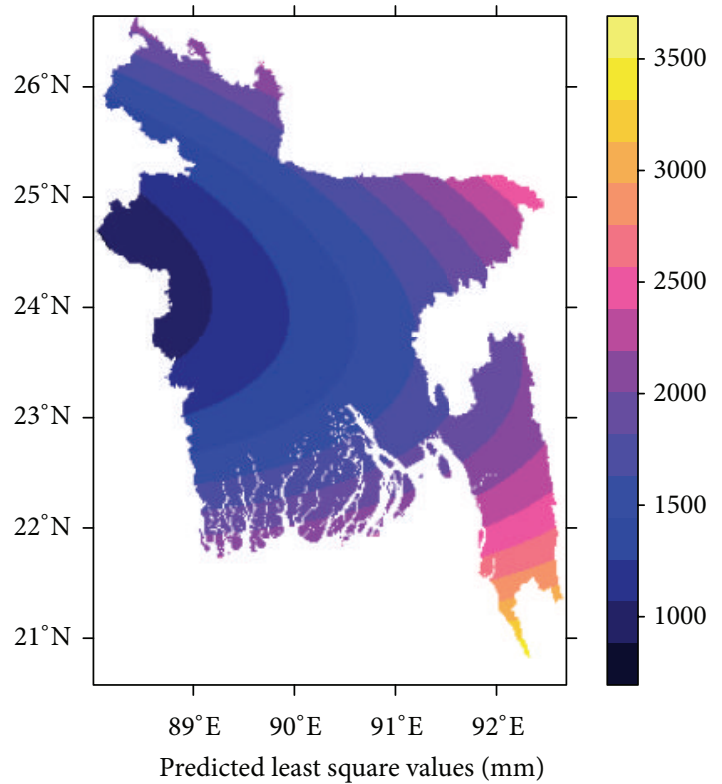

Mean trend-longitude: $-77.28 \mathrm{~mm} \mathrm{dd}^{-1}$ Mean trend-latitude: $314.58 \mathrm{~mm} \mathrm{dd}^{-1}$

(b)

FIgURE 7: Mean trend surfaces of (a) TXx and (b) PRCPTOT with gridded mean indices values, fitted by the two-dimensional least square approach with the mean intercepts and mean trend (slope) values.

range. Since 1990 and until 2007, the increasing trends (+ slopes) have been decreasing, and most likely it will continue decreasing in the next decade. These results illustrate that the spatial variability of the monsoon precipitation in Bangladesh is highly discontinuous despite of the spatial trends, but no evidence of the shift of the precipitation regime has been observed. Precipitation by nature is a very noisy phenomenon, and therefore high variation in the tendency of the spatial trend of the PRCPTOT is expected. But it is also important to consider that the rain-fed agriculture of
Bangladesh is highly and adversely affected by the intense spatial variation of the monsoon precipitation. This also creates dilemma in the flood mitigation planning.

The mean least square surfaces of the TXx and PRCPTOT considering the trends along latitudes and longitudes during the time period of 1948-2007 have been computed and presented in Figure 7 . The surfaces represent the actual mean trend behavior of the indices and thereby the expected climate regime of summer temperature and monsoon precipitation in Bangladesh. According to the computed surfaces, 
the summer maximum temperature in Bangladesh varies from $44^{\circ} \mathrm{C}$ to $32^{\circ} \mathrm{C}$ in the spatial direction from the west to the east of the country. The monsoon precipitation of the country varies from $700 \mathrm{~mm}$ to $3800 \mathrm{~mm}$ in the spatial direction from the midwest to the north-east and southeast of the country. Therefore, both of the indices show high spatial dependence in their behavior. The western regions of the country are the warmest, and the south-eastern and eastern regions of the country are the coolest in summer. Heat waves and droughts are most likely to occur in the western regions from this point of view. In addition, these regions experience the least monsoon precipitation, which will decrease the rain-fed crop production potentials in those regions and will create severe scarcity of water resources. But the combined phenomena increase the tea production potentials in the north-eastern regions of the country, though the observed shift in the temperature regime which resulted in the temporal interpolation might decrease this potential.

3.3. Discussion of the Results. According to the results obtained, there is a clear significant spatial trend in both of the climatic indices' tendency and variability over Bangladesh. The summer maximum temperature decreases, and the monsoon precipitation increases towards the southern coastal zone and the eastern hill tract zone of the country. These particular spatial trends of the indices are describable from the geographic location and terrain distribution in Bangladesh and in the neighboring countries, as presented in Figure 8. The southern periphery of the country is bordered by the Bay of Bengal, which mingles with the Indian Ocean at the far south. The eastern periphery of the country is characterized by the hills, which are further extended to the small mountains of Assam and Mizoram regions of India. The expansion of the ocean in the south and hills at the east of Bangladesh are presented in blue and green legends, respectively (Figure 8). Another important terrain characteristic is the location of Mount Himalaya in Nepal, close to the north-western periphery of the country. From the perspective of geographic location, Bangladesh is situated in the windward part of the monsoon wind. The funnelshaped exposure to the ocean allows plenty of rain-wind to propagate over the country and finally obstructed by the elevated mountains causing heavy rainfall in monsoon.

Therefore the highest monsoon precipitation occurs in the eastern part of the country because of geographical closeness to the mountainous area. Mount Himalaya has also an impact, which is visible in the relative higher monsoon precipitation in the neighboring areas at the typical north of Bangladesh from Figures 5 and 7. Closeness to the ocean leads to the higher monsoon precipitation events in the southern coastal zones than in the northern zones. And due to the less precipitation events and higher distance from the mountains, the western and northern parts of the country experience higher summer maximum temperatures. This can also be explained by the lapse rate of temperature phenomenon [42], which increases the temperature with the decreasing elevation. So, despite Bangladesh being a flat region, altitudes have a clear impact on the precipitation and temperature although the correlation of the station altitudes with the indices has been resulted insignificant. This contradiction has resulted because of the fact that the precise altitudes of the meteorological station locations do not represent the altitudes of the corresponding geographical areas and are below $50 \mathrm{~m}$. More importantly, none of the stations is located in the high elevated hills which could represent the correlated values of the indices with altitudes. The bounded continuum of precipitation and lapse rate of temperature should be taken into account for such analyses, which are subject to further research on the distribution of the climate indices in Bangladesh. The number of meteorological stations available in the country is not enough to predict spatiotemporal climatic trend with acceptable accuracy [43]. Innovative and complex models have to be adapted to design climate variability in Bangladesh more accurately. The observations from the stations of neighboring countries can be taken into account to predict the climate trend into larger spatial extent, which might bring interesting results in the spatial trends inside the boundary of Bangladesh.

An increase in the spatial trends of TXx and a decrease in the spatial trends of PRCPTOT until the 1980s have been observed from the temporal interpolation. Since then, until the current stage, the spatial trends of TXx and PRCPTOT are in the decreasing and increasing stages, respectively. As previous studies on Bangladesh represent the increasing temporal trend in temperatures and monsoon precipitation, the results from this study represent an alarming stage of climate change in the country. In light of the increasing temporal trend and decreasing spatial trend of TXx, it is comprehensible that the summer maximum temperature is increasing in the relative cooler regions and decreasing in the warmest regions of the country. This will entail a clear climatic shift in terms of temperature in Bangladesh, which is devastating for such an agriculturally dependent economy. While, in light of the increasing temporal and spatial trend of PRCPTOT, it can be clearly stated that the monsoon precipitation is increasing more and more in the wet regions and decreasing in the dry regions of the country. This will entail the increasing flood risk in the wet regions and drought risk in the dry regions and put the underground water table and soil moisture into risk since they are highly dependent on the monsoon precipitation. The case might be that the TXx and PRCPTOT are increasing in time in all the regions of the country, which depicts the much higher increase in TXx and PRCPTOT in the relative cooler and wet southern and eastern regions of the country. But the situation of climate change and threats due to the climatic shift remain the same.

The mean spatial trends of TXx observed in the country are $-1.13^{\circ} \mathrm{C} \mathrm{dd}^{-1}$ along longitude and $0.22^{\circ} \mathrm{C} \mathrm{dd}^{-1}$ along latitude, whereas the mean spatial trends of PRCPTOT observed are $314.58 \mathrm{~mm} \mathrm{dd}^{-1}$ along longitude and $-77.28 \mathrm{~mm} \mathrm{dd}^{-1}$ along latitude. These trends represent the complete opposite continuous spatial variation of these climate phenomena along the same axes. But the spatial trend of TXx along latitude has shifted to the opposite direction since 2000. This indicates that the southern coastal regions of the country have been experiencing higher summer maximum temperature than the northern regions since 2000. Generally, the northern 


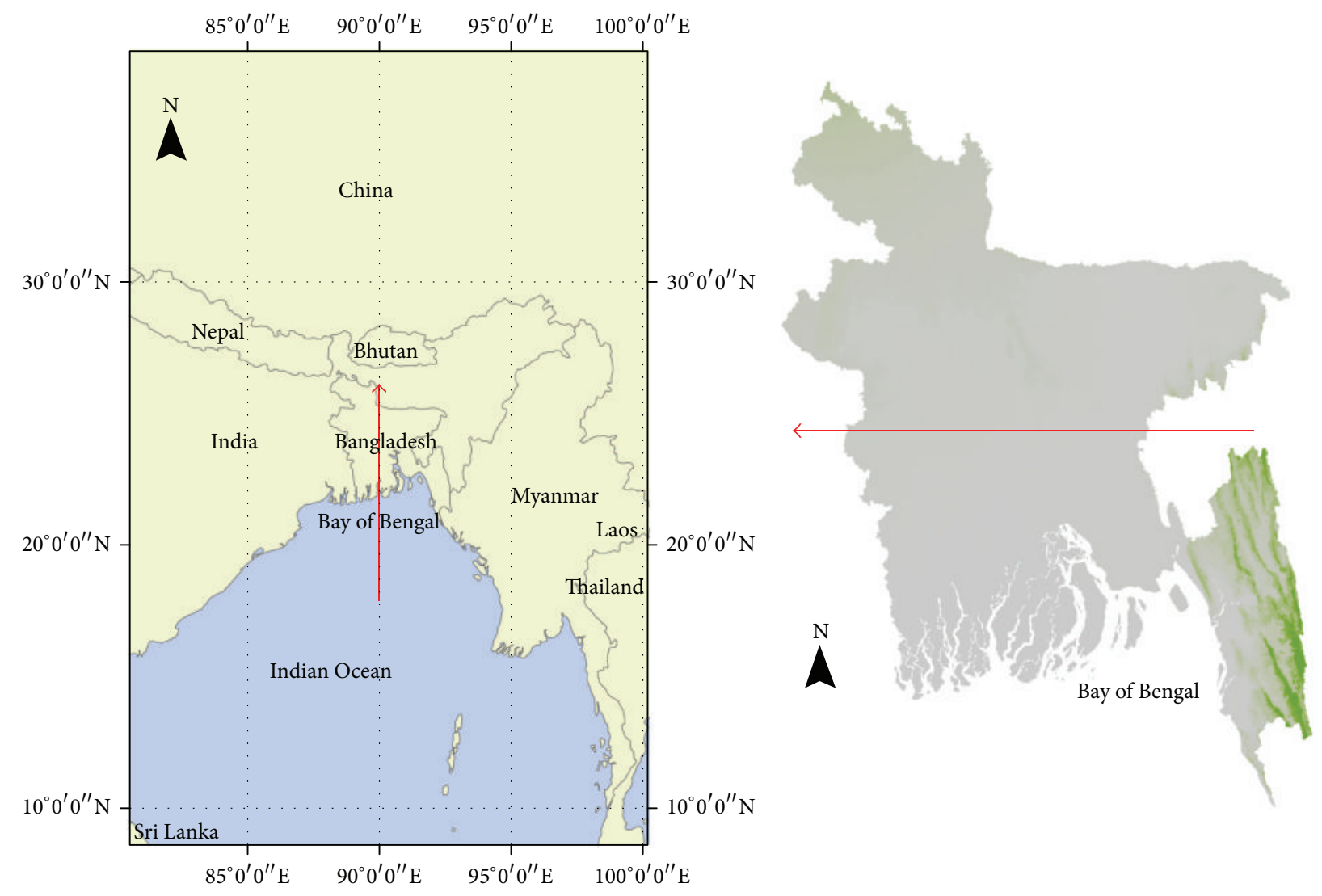

Figure 8: Geographic coastal and windward location of Bangladesh in relation to the Indian Ocean, Mount Himalaya, and other small mountains in India in the eastern border. The ocean is represented by blue, and hills inside Bangladesh boundary at the southeastern part are represented by green legends. The directions of both arrows represent the increase in TXx and decrease in PRCPTOT.

regions of the country represent the warmer regions; therefore there has been a clear shift in the temperature regime of Bangladesh. The study shows conformant results in the change of temperature and precipitation regimes to Bhowmik and Cabral's [44], Shahid's [22], and the other studies' results discussed in Section 1.

\section{Conclusion}

Previous studies have proved that one of the most important questions regarding climatic events is whether their occurrence is changing over space and time, and can be characterized by their frequency and statistical significance. This paper presents analyses of the spatial trends in two different annual indices representing summer temperature and monsoon precipitation for Bangladesh. The analyses have been conducted using long-term datasets for 34 meteorological stations under quality control, in general, for a temporal extent between 1948 and 2007.

As predicted by IPCC [7], increases in climate stress events such as floods, droughts, and heat waves will pose further challenges to South-Asian farmers. IPCC [7] also reveals a decrease of about $20 \%$ in precipitation at the high latitudes in most subtropical land regions. Bangladesh, being a subtropical South-Asian country, entails similar risk of climate change to the farmers, who are contributing significantly to the national GDP. In light of the results from this study, many regions of the country will lose their particular crop productivities. Bhowmik and Costa [45] have already discovered the decrease in the nonrain-fed irrigated crop production with the decrease in precipitation in Bangladesh. Further threats are most likely to take place in the near future, which must be taken into account in the climate resilience activities in the country.

There are other indices available for temperature events than TXx, which are urgent to analyze for Bangladesh to track the actual change in temperature. Nevertheless, it is difficult to forecast regional variability of climate phenomena and their potential effects on agriculture by using global climate models. Such regional studies on Bangladesh using the regional datasets will bring benefit to the climate variability analyses for South Asia and eventually for the world.

\section{Acknowledgments}

This study has been carried out in the framework of the European Commission, Erasmus Mundus Program, Master of Science in Geospatial Technologies, project no. 20070064. The author acknowledges Ana Cristina Costa, Edzer Pebesma, Jorge Mateu, and Pedro Cabral for their continuous 
support to shape this research work. The author would like to thank ISRN Atmospheric Sciences for providing with the opportunity to share this research.

\section{References}

[1] C. A. C. dos Santos, C. M. U. Neale, T. V. R. Rao, and B. B. da Silva, "Trends in indices for extremes in daily temperature and precipitation over Utah, USA," International Journal of Climatology, vol. 31, no. 12, pp. 1813-1822, 2011.

[2] C. K. Folland, T. R. Karl, J. R. Christy et al., Observed Climate Variability and Change. Climate Change 2001: The Scientific Basis. Contribution of Working Group I to the Third Assessment Report of the Intergovernmental Panel on Climate Change, Cambridge University Press, Cambridge, UK, 2001.

[3] L. V. Alexander, P. Hope, D. Collins, B. Trewin, A. Lynch, and N. Nicholls, "Trends in Australia's climate means and extremes: a global context," Australian Meteorological Magazine, vol. 56, no. 1, pp. 1-18, 2007.

[4] M. Hulme, T. J. Osborn, and T. C. Johns, "Precipitation sensitivity to global warming: comparison of observations with Had CM2 simulations," Geophysical Research Letters, vol. 25, no. 17, pp. 3379-3382, 1998.

[5] F. Lambert, P. Stott, and M. Allen, "Detection and attribution of changes in global terrestrial precipitation," Geophysical Research Abstracts, vol. 5, Article ID 06140, 2003.

[6] Intergovermental Panel on Climate Change (IPCC), "Climate change 2001: impacts, adaptation and vulnerability," in Contribution of Working Group II to the Third Assessment Report of the Intergovernmental Panel on Climate Change, Cambridge University Press, Cambridge, Mass, USA, 2001.

[7] Intergovermental Panel on Climate Change (IPCC), "Climate change 2007: impacts, adaptation and vulnerability," in Contribution of Working Group II to the Fourth Assessment Report of the Intergovernmental Panel on Climate Change, M. L. Parry, O. F. Canziani, J. P. Palutikof, P. J. van der Linden, and C. E. Hanson, Eds., p. 976, Cambridge University Press, Cambridge, UK, 2007.

[8] A. Tarhule and M. K. Woo, "Changes in rainfall characteristics in northern Nigeria," International Journal of Climatology, vol. 18, no. 11, pp. 1261-1271, 1998.

[9] M. Haylock and N. Nicholls, "Trends in extreme rainfall indices for an updated high quality data set for Australia, 1910-1998," International Journal of Climatology, vol. 20, pp. 1533-1541, 2000.

[10] G. M. Griffiths, M. J. Salinger, and I. Leleu, "Trends in extreme daily rainfall across the South Pacific and relationship to the South Pacific convergence zone," International Journal of Climatology, vol. 23, no. 8, pp. 847-869, 2003.

[11] T. J. Osbom, M. Hulme, P. D. Jones, and T. A. Basnett, "Observed trends in the daily intensity of United Kingdom precipitation," International Journal of Climatology, vol. 20, no. 4, pp. 347-264, 2000.

[12] S. S. Roy and R. C. Balling, "Trends in extreme daily precipitation indices in India," International Journal of Climatology, vol. 24, no. 4, pp. 457-466, 2004.

[13] M. H. K. Chowdhury and S. K. Debsharma, "Climate change in Bangladesh-a statistical review," in Report on the IOCUNEP Workshop on the Impacts of Sea Level Rise due to Global Warming, NOAMI, 1992.

[14] D. Braun, Bangladesh, India Most Threatened by Climate Change, Risk Study Finds, National Geographic, 2010.
[15] C. Yao, W. Qian, S. Yang, and Z. Lin, "Regional features of precipitation over Asia and summer extreme precipitation over Southeast Asia and their associations with atmospheric-oceanic conditions," Meteorology and Atmospheric Physics, vol. 106, no. 1, pp. 57-73, 2010.

[16] A. M. G. Klein Tank, T. C. Peterson, D. A. Quadir et al., "Changes in daily temperature and precipitation extremes in central and south Asia," Journal of Geophysical Research D, vol. 111, no. D16, Article ID D16105, 2006.

[17] A. M. Hussain and N. Sultana, "Rainfall distribution over Bangladesh stations during the monsoon months in the absence of depressions and cyclonic storms," Mausam, vol. 47, pp. 339348, 1996.

[18] Bangladesh Bureau of Statistics (BBS), Statistical Pocket Book Bangladesh, 2009.

[19] B. Parthasarathy, N. A. Sontakke, A. A. Monot, and D. R. Kothawale, "Droughts/floods in the summer monsoon season over different meteorological subdivisions of India for the period 1871-1984," Journal of Climatology, vol. 7, no. 1, pp. 5770, 1987.

[20] S. Karmakar and M. L. Shrestha, Recent Climate Change in Bangladesh, SMRC no.4, SAARC Meteorological Research Center, Dhaka, Bangladesh, 2000.

[21] N. M. Mia, "Variations of temperature of Bangladesh," in Proceedings of SAARC Seminars on Climate Variability in the South Asian Region and Its Impacts, SMRC, Dhaka, Bangladesh, 2003.

[22] S. Shahid, "Spatio-temporal variability of rainfall over Bangladesh during the time period 1969-2003," Asia-Pacific Journal of Atmospheric Science, vol. 45, pp. 375-389, 2009.

[23] S. Shahid, "Trends in extreme rainfall events of Bangladesh," Theoretical and Applied Climatology, vol. 104, no. 3-4, pp. 489499, 2011.

[24] W. Wang, X. Chen, P. Shi, and P. H. A. J. M. van Gelder, "Detecting changes in extreme precipitation and extreme streamflow in the Dongjiang River Basin in southern China," Hydrology and Earth System Sciences, vol. 12, no. 1, pp. 207-221, 2008.

[25] M. E. Mann, R. S. Bradley, and M. K. Hughes, "Global-scale temperature patterns and climate forcing over the past six centuries," Nature, vol. 392, no. 6678, pp. 779-787, 1998.

[26] J. Chen, A. D. Del Genio, B. E. Carlson, and M. G. Bosilovich, "The spatiotemporal structure of twentieth-century climate variations in observations and reanalyses-part I: long-term trend," Journal of Climate, vol. 21, no. 11, pp. 2611-2633, 2008.

[27] D. C. Norton and S. J. Bolsenga, "Spatiotemporal trends in lake effect and continental snowfall in the Laurentian Great Lakes, 1951-1980," Journal of Climate, vol. 6, no. 10, pp. 1943-1956, 1993.

[28] T. C. Peterson, C. Folland, G. Gruza, W. Hogg, A. Mokssit, and N. Plummer, "Report on the activities of the Working Group on Climate Change Detection and Related Rapporteurs 1998-2001," Tech. Rep. WCDMP-47, WMO-TD, 1071, World Meteorological Organization, Geneva, Switzerland, 2001.

[29] X. Zhang, Climate Research Division, Environment Canada under the auspices of ETCCDI, ETCCDI/CRD Climate Change Indices, August 2011, http://cccma.seos.uvic.ca/etccdi/ index.shtml.

[30] Disaster Management Information Center (DMIC) of Comprehensive Disaster Management Program (CDMP), Bangladesh Meteorological Department, January 2012, http://www.bmd .gov.bd/index.php. 
[31] Institute for Statistics and Mathematics, WU Wien, (ISMWUWW), "The R Project for Statistical Computing," January 2012, http://www.r-project.org/.

[32] M. R. Haylock, T. C. Peterson, L. M. Alves et al., "Trends in total and extreme South American rainfall in 1960-2000 and links with sea surface temperature," Journal of Climate, vol. 19, no. 8 , pp. 1490-1512, 2006.

[33] X. Zhang and F. Yang, RClimDex (1.0) User Guide, Climate Research Branch Environment, Ontario, Canada, 2004.

[34] N. Plummer, M. J. Salinger, N. Nicholls et al., "Changes in climate extremes over the Australian region and New Zealand during the twentieth century," in Weather and Climate Extremes: Changes, Variations and a Perspective from the Insurance Industry, T. R. Karl, N. Nicholls, and A. Ghazi, Eds., pp. 183-202, Kluwer Academic publishers, 1999.

[35] Q. You, S. Kang, E. Aguilar et al., "Changes in daily climate extremes in China and their connection to the large scale atmospheric circulation during 1961-2003," Climate Dynamics, vol. 36, no. 11-12, pp. 2399-2417, 2011.

[36] E. Alexander, The Third World Natural Disasters, Kluwer Academic Publishers, Dordrecht, The Netherlands, 1999.

[37] Ministry of Environment and Forests Government of the People's Republic of Bangladesh (MEF), Bangladesh Climate Change Strategy and Action Plan, Ministry of Environment and Forests, Government of the People's Republic of Bangladesh, Dhaka, Bangladesh, 2008.

[38] The World Bank (WB), "Bangladesh: Economics of Adaptation to Climate Change Study," January 2012, http://climate change.worldbank.org/content/bangladesh-economics-adaptation-climate-change-study/.

[39] S. W. Greenhouse and S. Geisser, "On methods in the analysis of profile data," Psychometrika, vol. 24, no. 2, pp. 95-112, 1959.

[40] M. F. Hutchinson, "Interpolating mean rainfall using thin plate smoothing splines," International Journal of Geographical Information Systems, vol. 9, no. 4, pp. 385-403, 1995.

[41] P. A. Hancock and M. F. Hutchinson, "Spatial interpolation of large climate data sets using bivariate thin plate smoothing splines," Environmental Modelling and Software, vol. 21, no. 12, pp. 1684-1694, 2006.

[42] C. J. Willmott, C. M. Rowe, and W. D. Philpot, "Small-scale climate maps: a sensitivity analysis of some common assumptions associated with grid-point interpolation and contouring," American Cartographer, vol. 12, no. 1, pp. 5-16, 1985.

[43] A. K. Bhowmik, "A comparison of Bangladesh climate surfaces from the geostatistical point of view," ISRN Meteorology, vol. 2012, Article ID 353408, 20 pages, 2012.

[44] A. K. Bhowmik and P. Cabral, "Statistical evaluation of spatial interpolation methods for small-sampled region: a case study of temperature change phenomenon in Bangladesh," in Computational Science and Its Applications-ICCSA, B. Mugante, O. Gervasi, A. Iglesias, D. Taniar, and B. O. Apduhan, Eds., Lecture Notes in Computer Science, pp. 44-59, Springer, New York, NY, USA, 2011.

[45] A. K. Bhowmik and A. C. Costa, "A geostatistical approach to the seasonal precipitation effect on boro rice production in Bangladesh," International Journal of Geosciences, vol. 3, pp. 443-462, 2012. 

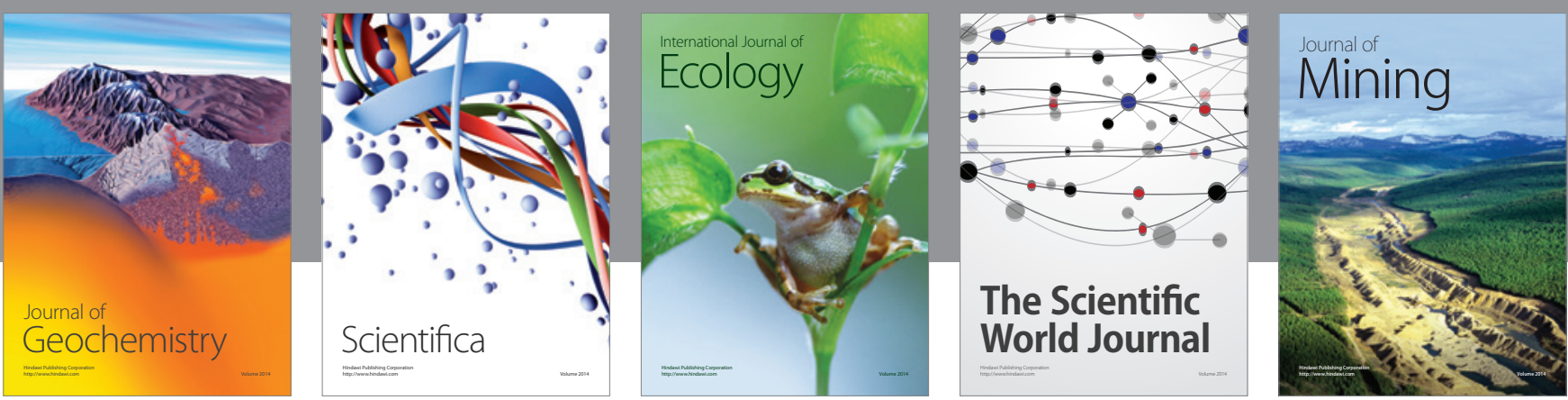

The Scientific World Journal
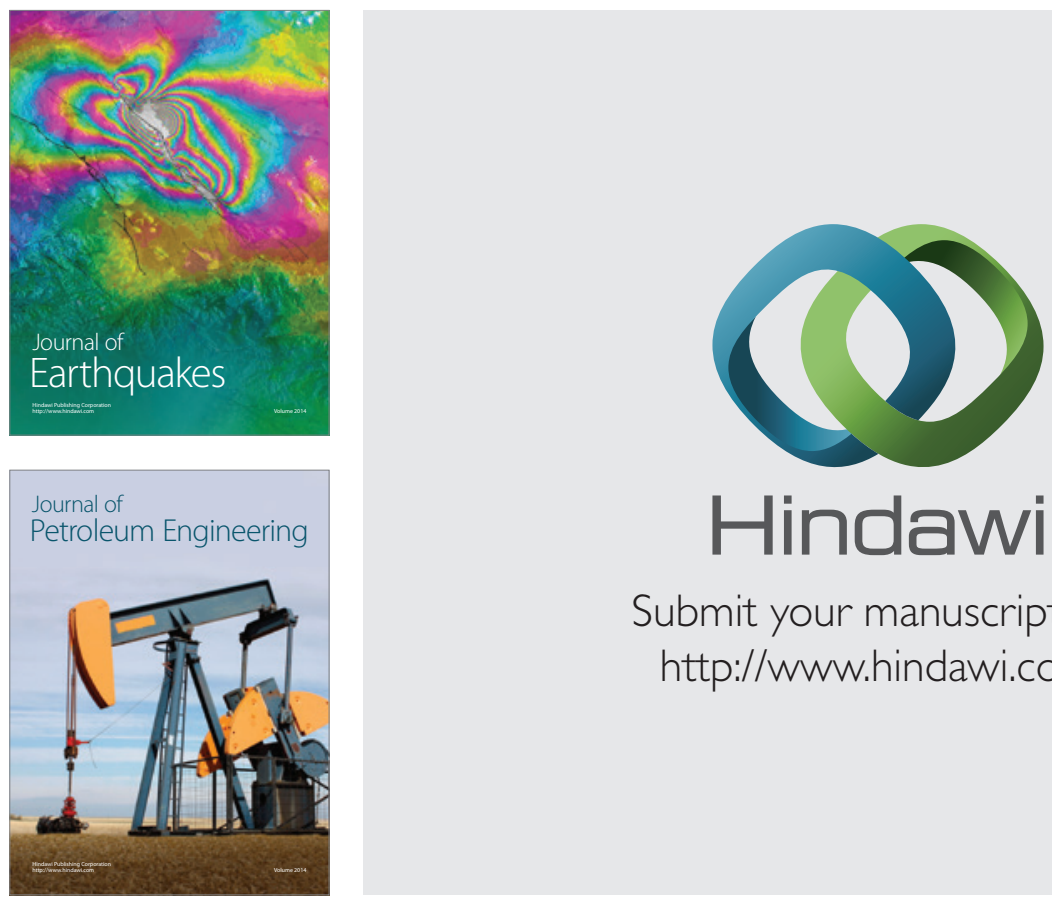

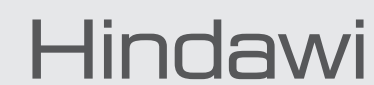

Submit your manuscripts at

http://www.hindawi.com
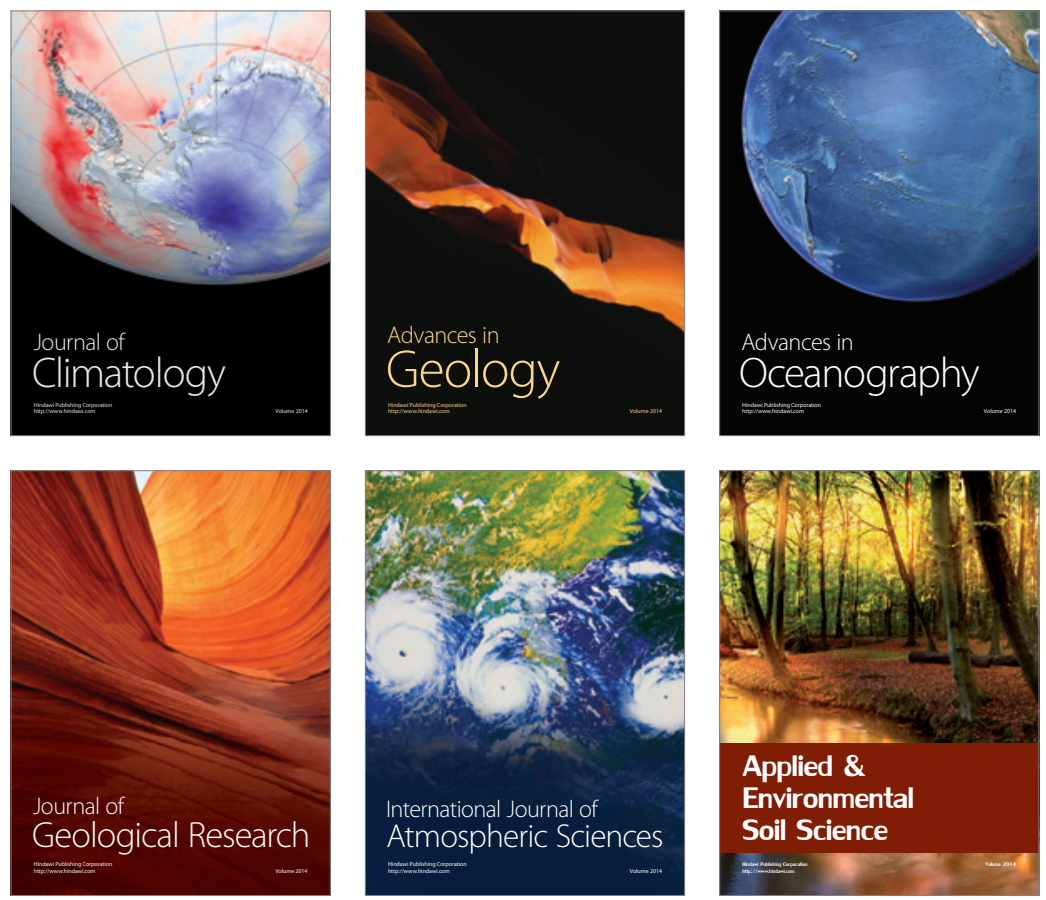
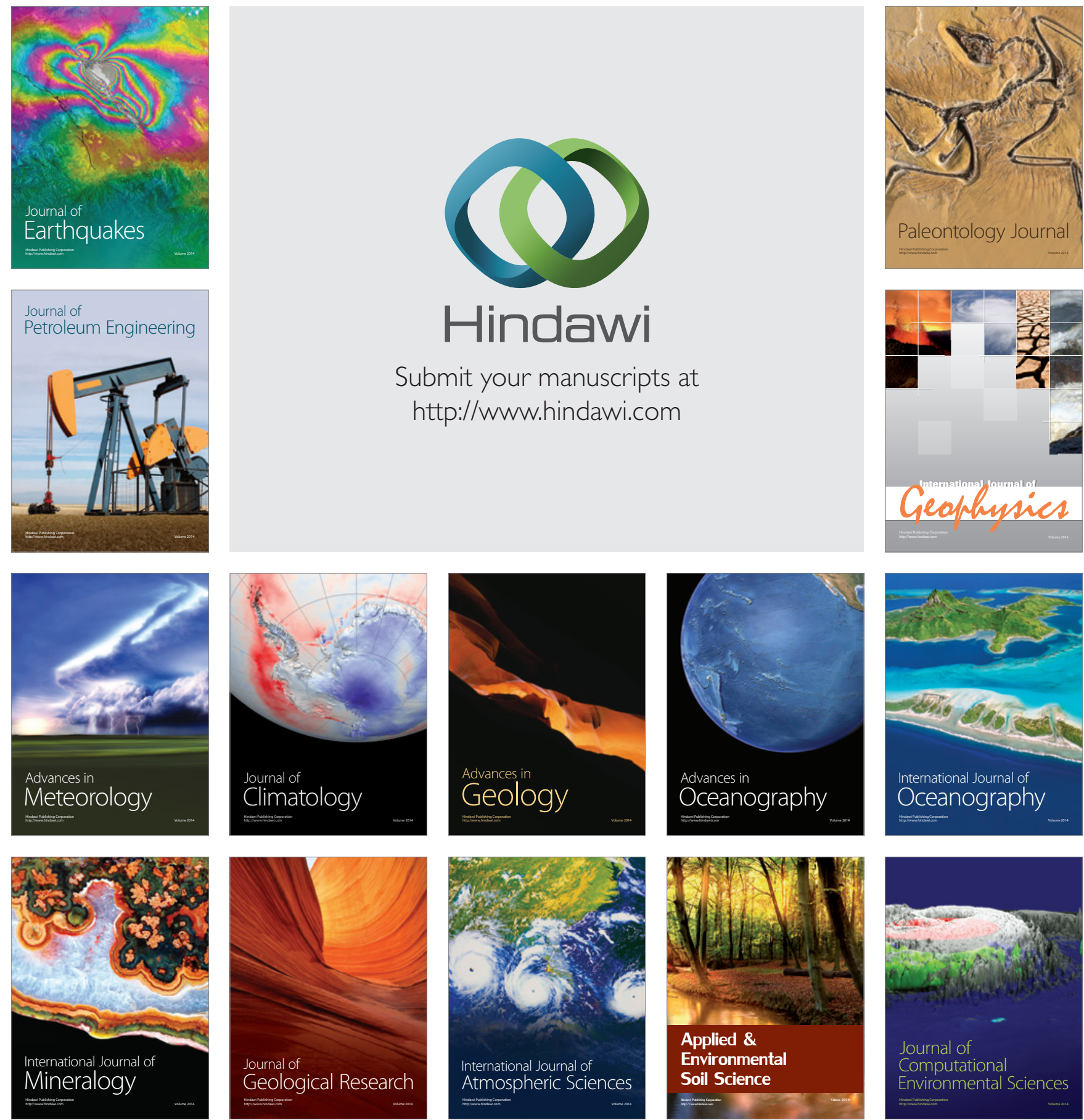